\title{
Kanatlı-Borulu Isı Değiştiricilerinde Çukurlu/Çıkıntılı Kanat ile Isı Transfer Performansının Arttırılması
}

\author{
Ahmet Ümit Tepe* \\ * Sinop Üniversitesi, Mühendislik ve Mimarlık Fakültesi, Enerji Sistemleri Mühendisliği Bölümü, Sinop/Türkiye, (ORCID: 0000-0001-7626-6348), \\ autepe@sinop.edu.tr
}

(Illk Geliş Tarihi 5 Şubat 2021 ve Kabul Tarihi 4 Nisan 2021)

(DOI: $10.31590 /$ ejosat.874885)

ATIF/REFERENCE: Tepe, A. Ü. (2021). Enhancement of Heat Transfer Performance for Fin-Tube Heat Exchangers Using Dimpled/Protruding Fin Surface. Avrupa Bilim ve Teknoloji Dergisi, (23), 401-414.

Öz

Bu çalışmada kanatlı-borulu 1sı değiştiricisinde çukurlu/çıkıntılı kanatın 1sı transfer performansına ve akış karakteristiklerine etkisi sayısal olarak incelenmiştir. En uygun tasarım parametresini belirlemek için kanat üzerine dairesel ve 0,667 ile 1,50 olmak üzere iki farklı ovallik oranlı $(a / b)$ çukurlar çift sıralı olarak yerleştirilerek ısı transfer performansına etkisi araştırılmıştır. Dairesel çukurun çapı 2,8 mm olarak belirlenmiştir. Oval çukurların kesit alanı ise dairesel çukurla eşit tutulmuştur. Hesaplamalar 500, 1000, 1500 ve 2000 olmak üzere 4 farklı Reynold (Re) sayısında laminar akış rejiminde yapılmışıtır. Sayısal hesaplamalar Ansys Fluent 19.2 ile RNG $k$ türbülans modeli kullanılarak gerçekleştirilmiştir. Ortalama Nusselt sayısı $(\overline{N u})$, yüzey üzerinde yanal ortalamalı $N u$ sayısı dağılımları, termal performans faktörü $(T P F)$ ve akış karakteristikleri ayrıntılı olarak incelenmiştir. Sonuçlar çukur olmayan düz yüzeyli kanatçık ile karşılaştırılmıştır. Sayısal sonuçlar, yüzey üzerine yerleştirilen çukurların/çıkıntıların düz yüzeye göre 1sı transferini \%26,63'e kadar arttırdığını ortaya koymuştur. Bununla birlikte, $T P F$ sonuçlarına göre 1sı transferi artışında en uygun tasarımın dairesel çukurlu/çıkıntılı kanat tasarımının olduğu tespit edilmiştir.

Anahtar Kelimeler: Isı Değiştirici, Isı Transferi, Girdap Üreteci, Hesaplamalı Akışkanlar Dinamiği.

\section{Enhancement of Heat Transfer Performance for Fin-Tube Heat Exchangers Using Dimpled/Protruding Fin Surface}

\begin{abstract}
In this study, effect of dimpled/protruding fin on heat transfer performance and flow characteristics for a fin-tube heat exchanger was numerically investigated. Circular dimple/protrusion and two different dimple/protrusion aspect ratio $(a / b)$ such as 0.667 and 1.50 in a double row arrangement were investigated in order to obtain the most feasible dimple/protrusion design parameter. The diameter of the circular dimple is $2.8 \mathrm{~mm}$. The cross-sectional area of the oval dimples is equal to the cross-sectional area of the circular dimples. Simulations were carried out in the laminar flow conditions at four Reynolds $(R e)$ numbers including 500, 1000,1500 and 2000. Numerical calculations were performed with Ansys Fluent 19.2 using RNG $k-\varepsilon$ turbulence model. Average Nusselt number $(\overline{N u})$, lateraly-averaged $N u$ number distributions on the surface, thermal performance factor (TPF) and flow characteristics were comprehensively investigated. Results were compared with the flat fin surface. Numerical results revealed that dimple/protrusion fin increases heat transfer up to $26.63 \%$ compared to the flat surface. However, it was determined that the most feasible design for enhancement heat transfer is circular dimpled/protruding fin design for the fin-tube heat exchangers according to $T P F$ results.
\end{abstract}

Keywords: Heat Exchanger, Heat Transfer, Vortex Generator, Computational Fluid Dynamics.

\footnotetext{
*Sorumlu Yazar: autepe@sinop.edu.tr
} 


\section{Giriş}

Kanatlı borulu 1Sı değiştiricileri otomobil, 1sıtma-soğutma sistemleri, enerji üretim santralleri, ısı geri kazanım gibi endüstrinin birçok alanında etkin bir şekilde sıcak akışkandan soğuk akışkana enerjinin aktarılmasını sağlayan önemli tesisat elemanlarıdır. Etkinliği yüksek bir ısı değiştirici sadece üretim maliyetinin düşmesiyle değil aynı zamanda daha düşük hacimli tasarımıyla uygulamada da önemli avantajlar sağlar. Bu nedenle 1S1 değiştiricilerin etkinliğini arttırmaya yönelik çalışmalar önem taşımaktadır.

Yüzey üzerine yerleştirilen çukurlar türbin kanatlarının soğutulması gibi nispeten düşük basınç kaybının önemli olduğu alanlarda etkin bir şekilde ısı transferini arttırmaktadır (Jing vd., 2018; Singh vd., 2016; G. Xie vd., 2010). Bu nedenle çukurlu kanatların kanatlı-borulu 1S1 değiştiricilerinde de 1S1 transfer performansının iyileştirme potansiyeli bulunmaktadır.

Kanatl1-Borulu 1s1 değiştiricilerinde genellikle üretim kolaylığı nedeniyle kanatların imalatı düz yapılır. Buna karşın, yapılan çalışmalar düz yüzey üzerine yerleştirilen engellerin 1sı transferini önemli ölçüde artıracağını ortaya koymaktadır (Caliskan, 2013; Eiamsa-Ard vd., 2011; Wan vd., 2015). Literatürde 1Sı transferinin arttırılmasına yönelik olarak kanat üzerine girdap üretecinin yerleştirildiği çalışmalara yoğunlaşılmış ve bu çalışmaların önemli bir bölümü dairesel kesitli veya oval kesitli boruya sahip kanatl1-borulu 1sı değiştiricilerle ilgilidir (Chu vd., 2009; He vd., 2012; H. Huisseune vd., 2013; Henk Huisseune vd., 2013; J. Li vd., 2011; M. J. Li vd., 2014; C. N. Lin vd., 2008; Z. M. Lin vd., 2015; Sinha vd., 2016; Tiwari vd., 2003). Benzer şekilde, düz kanal yapısına sahip kanatl1-borulu 1sı değiştiricileri ile ilgili de 1sı transferini arttırmaya yönelik kanat üzerine girdap üretecinin yerleştirildiği çalışmalar yapılmıştır. Yapılan deneysel bir çalışmada düz yüzey üzerine yerleştirilen delta kanatçıkların düşük Re sayılarında 1sı transferi \%50-60 kadar arttırdığ görülmüştür (Gentry vd., 1997). Bir diğer çalışmada düz yüzeyli boruya sahip kanatl1-borulu ısı değiştiricilerinde kanatçık üzerine yerleştirilen girdap üretecinin 1sı transfer performansına olan etkisi incelenmiştir (L. M. Chang vd., 2009). Isı değiştiricilerinde boru etrafına testere dişi geometrisine sahip kanatçıkların 1sı transferi ve akış karakteristiklerine etkisinin araştırıldığı bir diğer çalışmada, akışa göre $15^{\circ}$ burulmuş kanatçık tasarımı 1sı transferini iyileştirmiş, ancak burulma açısı $15^{\circ}$ 'nin üzerine çıktığında basınç kaybındaki artış nedeniyle 1sı transfer performansının kötüleştiği görülmüştür (Lemouedda vd., 2011). Düz kanal kesitli boruya sahip kanatl1-borulu 1sı değiştiricilerinde düz kanat üzerine yerleştirilen uzunlamasına delta kanatçıklı girdap üreteci araştırılmış ve yapılan çalışmada delta kanatçıkların ısı transferini \%21-60, TPF'ü ise 1.31'e kadar arttırdığı belirlenmişlertir (Du vd., 2013, 2014). Bir diğer çalışmada ise düz yüzey üzerine yerleştirilen delta kanatçıkların hücum açılarının 1Sı transferine etkisi araştırılmıştır. Yapılan çalışmada hücum açısının artması yüzeyin hem girişinde hem de çıkışında 1sı transfer performansını düşürdüğü belirlenmiştir $(\mathrm{Wu}$ vd., 2018). Düz yüzey üzerine dik olarak yerleştirilmiş bir çift dikdörtgen kesitli esnek kanatçıkların 1sı transfer performansına etkisinin türbülanslı akış rejimi şartlarında incelendiği bir deneysel çalışmada, daha $\mathrm{s} 1 \mathrm{k}$ aralıklı kanatçıklar arasındaki mesafenin, yüzey üzerinde akışkanın hızını arttırması, daha yüksek türbülans yoğunluğu ve kinetik enerji ortaya çıkarması ve daha güçlü akış dalgalanmaları yaratması nedeniyle 1sı transferini arttırdığı sonucuna varılmıştır (Yang vd., 2020). Kavisli dikdörtgen kanatçıkların kompakt kanatlı-borulu 1S1 değiştiricilerinde akış ve 1sı transfer karakteristiklerinin laminar ve türbülanslı akış rejiminde sayısal olarak incelendiği bir diğer çalışmada ise, yüzeye yerleştirilen kavisli dikdörtgen kanatçıkların akış alanı içerisinde ikincil bir akış oluşturarak 1sı transferinin artmasına katkı bulunduğu belirlenmiştir (J. Xie vd., 2020). Bir diğer sayısal çalışmada ise yarık kanatçık ve girdap üretecinin en uygun tasarımı laminar akış rejiminde araştırılmıştır. Sayısal sonuçlar girdap üretecinin kullanılması düz yüzeye göre hem yüzeyin 1sı transferini hem de basınç kaybını arttırdığını göstermişstir. Ancak sonuçlar 1sı transfer performansındaki artışın daha baskın olduğu göstermektedir (Moreno vd., 2020). Yapılan bir diğer sayısal çalışmada düz borulu kompakt 1S1 değiştiricilerinde uzunlamasına delta kanatçıklı girdap üretecinin termal performansa etkisi laminar akış şartlarında incelenmiştir. $\mathrm{Bu}$ çalışmanın sayısal sonuçlarına göre yüzeye delta kanatçık ilave edilmesi 1sı transfer hızını \%52 arttırılabileceği sonucuna varılmıştır (Carpio vd., 2020). Üzerine dairesel delik açılmış üçgen ve dikdörtgen şekilli kanatçıkların kompact kanatl1-borulu 1S1 değiştiricilerinin 1S1 transfer performansına etkisinin araştırıldığı bir diğer sayısal çalışmada ise, kanat üzerine dairesel delik açılmasının thermo-hidrolik performansı arttırdığı tespit edilmiştir (Modi vd., 2020).

Sınır tabakanın düzenini bozmaya yönelik olarak yüzey üzerine yerleştirilen bu tür engeller aynı zamanda sistemin basınç kaybındaki artışı da beraberinde getirir. Bu nedenle 1sı transferini arttırmaya yönelik yapılacak tasarımların iyi bir ayrodinamik yapıya sahip olması gerekir. Bu amaçla literatürde yüzey üzerine yerleştirilen yarım küresel veya oval çukurların ısı transferine ve akış karakteristiklerine etkisi de araştırılmıştır. Bu konuda gerçekleştirilen bir sayısal çalışmada sistemin basınç kaybı düz yüzeye kıyasla üzerine çukur yerleştirilen yüzeyde sadece $\% 5$ artmasına rağmen 1S1 transferinin iki kat arttığ sonucuna varmışlardır (G. Xie vd., 2010). Bir diğer çalışmada ise üzerine çubuk-kanatçık yerleştirilen yüzeyde dairesel çukurların basınç kaybı ve 1sı transfer performansı deneysel olarak incelenmiştir. Deney sonuçları düz yüzeyli ve çubuk-kanatçıklı tasarıma göre dairesel çukurlu ve çubuk-kanatçıklı tasarımın 1S1 transfer performansını arttırdığını göstermektedir (Rao vd., 2012). Kanatlı-borulu 1sı değiştiricilerinde dairesel ve damla şeklinde oluşturulmuş çukurlu kanatların isı transfer performansına etkisinin incelendiği diğer bir çalışmada ise, damla şeklindeki çukurların dairesel çukura kıyasla 1sı transfer hızını daha fazla arttırdığı belirlenmiştir (Y. Xie vd., 2015).

Son zamanlarda kanatlı-borulu 1S1 değiştiricileri ile ilgili yapılan çalışmaların önemli bir bölümünde, akış alanı içerisinde girdap üretmek amacıyla kanat üzerine yerleştirilen farklı şekillerdeki kanatçık tasarımlarına odaklanılmıştır. Ancak çukurlu/çıkıntılı yüzeyler nispeten düşük basınç kaybı yaratması sayesinde kanatl1-borulu 1s1 değiştiricilerinde de 1s1 transfer performansını arttırma potansiyeli bulunmaktadır. Bu çalışmada çift sıralı çukurlu/çıkıntılı kanatçı̆̆a sahip kanatlı-borulu 1S1 değiştiricilerin 1sı transferine ve akış karakteristiklerine etkisi sayısal olarak incelenmiştir. Yapılan bu sayısal çalışma ile yarım küre ve oval şekilli çukurlu/çıkıntılı yüzeylerin sonuçları düz yüzeyli kanatçıkla karşılaştırılarak en uygun tasarım parametresi ortaya çıkarılmıştır. 


\section{Materyal ve Metot}

\subsection{Tasarım Parametreleri}

Kanatl1-borulu 1sı değiștirici ve hesaplamaya dâhil edilen tipik bir fiziksel modelin ölçüleri Şekil 1.'de gösterilmiştir. Isı değiştiricisinde içerisinden sıcak akışkan geçen boru düz duvar şekillidir ve baş kısımlarında yarıçap $r_{t}=5 \mathrm{~mm}$ 'dir. Borunun ve boru üzerine yerleştirilen kanatın uzunluğu $l=50 \mathrm{~mm}$, kalınlığı ise $t=0,4$ mm'dir. Kanatlar $1 \mathrm{~S} 1$ değiştiricisinin borusuna $H=6 \mathrm{~mm}$ aralıklarla yerleştirilmiştir. İki borunun merkezleri arasındaki mesafe $W=20 \mathrm{~mm}$ 'dir. Hesaplamalarda $2,80 \mathrm{~mm}$ iç çaplı dairesel çukur ile 0,667 ve 1,50 olmak üzere iki farklı ovallik oranına $(a / b)$ sahip oval çukurlar incelenmiştir. Çukurların boyutsuz derinlikleri $(D / d)$ ise 0,195 'dir. Çukurlar kanat üzerine akış doğrultusunca $p=12 \mathrm{~mm}$ aralıklarla yerleştirilmiştir. Yanal doğrultuda ise $s=4 \mathrm{~mm}$ aralıkla çukur yönü ters olacak şekilde çift sıralı olarak yerleştirilmiştir. Kanatın kalınlığı $t=0,40 \mathrm{~mm}$ olarak belirlenmiştir. $\mathrm{Bu}$ nedenle kanat üzerine oluşturulan çukur aynı zamanda kanadın diğer yüzünde çıkıntı oluşturmaktadır. Oluşan çıkıntının ise boyutsuz yüksekliği $H / d=0,265$ 'dir. Böylelikle, 1s1 transfer performansı kanatın bir yüzünde çukur, diğer yüzünde ise çıkıntı vasıtasıyla arttırılması sağlanmıştır. Akış alanı sınırlarında ters akışın hesaplamaları etkilememesi için hesaplama alanı girişte $45 \mathrm{~mm}$, çıkışta ise $95 \mathrm{~mm}$ kadar uzatılmıştır. Parametrik çalışmada incelenilen geometrilerin detayları ayrı ayrı Şekil 2.'de gösterilmiştir.

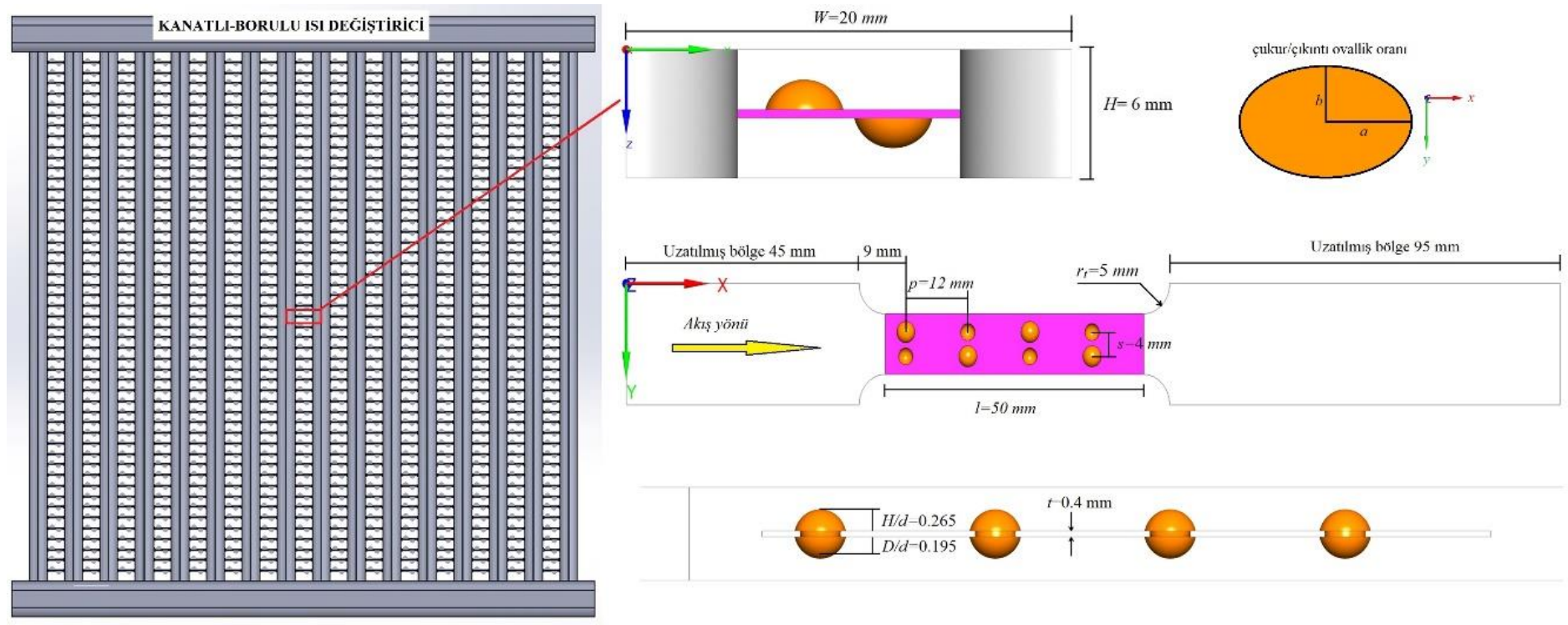

Şekil 1. Tipik bir fiziksel modelin ölçüleri.

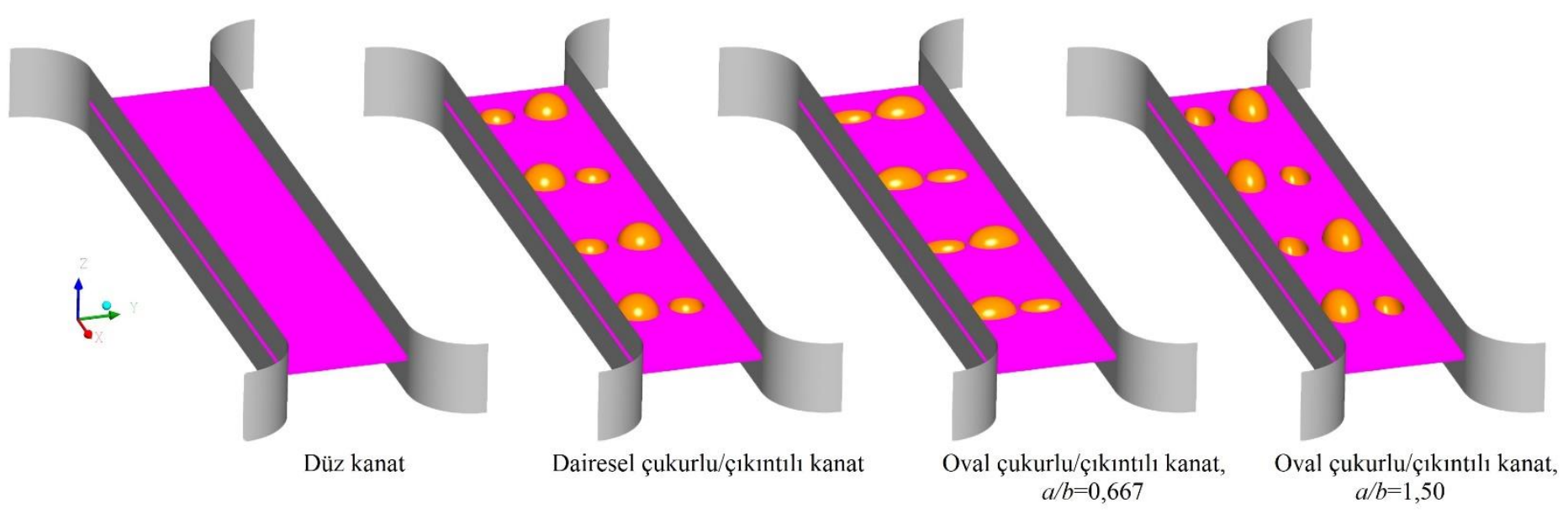

Şekil 2. Incelenen geometrik parametrelerin detaylart.

\subsection{Korunum Denklemleri}

Fiziksel model Ansys FLUENT 19.3 programında 3-D olarak oluşturulmuştur. Çözümler sürekli rejim şartlarında elde edilmiştir. Hesaplamalarda ışınım 1sı transferi ihmal edilmiştir. Akışın Re sayısı 2400'ün altında olması nedeniyle akış laminar akış rejimindedir (Çengel vd., 2015). Akışkan olarak hava kullanılmış ve havanın termofiziksel özelliklerinin sıcaklıkla değişmediği kabul edilmiştir.

Sayısal hesaplamalarda çözümü yapılan Reynolds-averaged Navier-Stokes denklemleri (RANS) aşağıdaki gibidir: 
Süreklilik denklemi:

$\frac{\partial u_{i}}{\partial x}=0,(i=1,2,3)$

Momentum denklemi:

$\frac{\partial\left(\rho u_{i} u_{j}\right)}{\partial x_{i}}=-\frac{\partial P}{\partial x_{j}}+\frac{\partial}{\partial x_{i}}\left(\mu \frac{\partial u_{j}}{\partial x_{i}}-\rho \overline{u_{\imath}^{\prime} u_{\jmath}^{\prime}}\right)$,

$(i, j=1,2,3 ; i \neq j)$

Enerji denklemi:

$\rho C_{p} u_{i} \frac{\partial T}{\partial x_{i}}=\frac{\partial}{\partial x_{i}}\left(k \frac{\partial T}{\partial x_{i}}\right)(i, j=1,2,3)$

Yukarıda yer alan denklemler Yakhod vd. (Yakhot vd., 1992) tarafından geliştirilen RNG $k-\varepsilon$ (Enhanced Wall Treatment duvar fonksiyonu ile birlikte) türbülans modeli kullanılarak çözülmüştür.

Is1 değiştiricisinin duvarlarından havaya aktarılan 1S1 transferinin hızı aşağıdaki gibidir:

$$
\dot{Q}_{\text {hava }}=\dot{m} C_{p, \text { hava }}\left(T_{\mathrm{c}}-T_{g}\right)
$$

Yukarıda yer alan denklemde $\dot{m}$ havanın kütlesel debisi, $C_{p, \text { hava }}$ ise havanın özgül ısısıdır. $T_{\zeta}$ ve $T_{g}$ sırasıyla havanın akış alanı sınırlarının çıkış ve girişindeki sıcaklıklarıdır. Isı değiştiricisinin duvarları ile akışkan arasında taşınım 1sı transfer hızı ise aşağıdaki gibi hesaplanır:

$$
\dot{Q}_{\text {taşınım }}=h A_{s}\left(T_{s}-T_{b}\right)
$$

Bu denklemde $T_{b}$ akışkanın yığın sıcaklığı olup $T_{b}=\left(T_{c ̧}+T_{g}\right) / 2$ ile belirlenir.

Eş. (4)'de yer alan ve 1sı değiştiricisinin duvarlarından havaya aktarılan ısı transfer hızı ile Eş. (5)'de yer alan taşınım ısı transfer hızı birbirine eşit olduğundan $\left(\dot{Q}_{\text {hava }}=\dot{Q}_{\text {taşınım }}\right)$, ortalama taşınım 1sı transfer katsayısı, $h$, aşağıdaki gibi tekrar yazılabilir:

$$
h=\frac{\dot{m} C_{p, \text { hava }}\left(T_{\mathrm{c}}-T_{g}\right)}{A_{S}\left(T_{S}-T_{b}\right)}
$$

Ortalama Nusselt $(\mathrm{Nu})$ sayısı ise aşağıdaki denklemden hesaplanır:

$$
N u=\frac{h d}{k}
$$

Burada $k$ havanın 1s1l iletkenlik katsayıs1, $d$ ise 1s1 transferinin incelendiği alanda kanalın hidrolik çapı olup Eş. (8)'den hesaplanabilir:

$$
d=\frac{4 A_{c}}{P}=\frac{2\left(W-2 r_{t}\right)(H-t)}{\left(W-2 r_{t}\right)+(H-t)}
$$

Reynold $(R e)$ sayısı ise aşağıdaki gibi hesaplanabilir:

$$
R e=\frac{u d}{v}
$$

Hesaplama alanının giriş ve çıkış sınırlarında türbülans yoğunluğu aşağıdaki gibi hesaplanır:

$$
I=0.16 R e^{-1 / 8}
$$

Sürtünme katsayısı, $f$, Eş. (11) ile hesaplanır:

$$
f=\frac{2}{l / d} \frac{\Delta P}{\rho u^{2}}
$$

Burada $\Delta P$ kanadın akış yönüne göre üst ucu ile $(x / d=6,96)$ alt ucu arasındaki $(x / d=13,93)$ basınç kaybıdır. $l$ ise Şekil 1.'de gösterildiği gibi kanatın uzunluğudur.

\subsection{Sayısal Çalışma}

Hesaplama alanı ve sınır koşulları Şekil 3.'de gösterilmiştir. Tam gelişmiş ana akış hesaplama alanına giriş sınırından $300 \mathrm{~K}$ sıcaklıkta girmektedir. Hesaplama alanı girişinde hız sınır koşulu tanımlanmıştır. Hesaplama alını çıkış sınırına ise basınç çıkışı sınır koşulu uygulanmıştır. Çıkışta gösterge basıncı 0'dır. Fiziksel model $y$-ekseni boyunca simetrik olduğundan $y$-ekseni sınırlarına simetrik sınır koşulu, $z$-ekseni boyunca ise periyodik olduğundan $z$-ekseni sınırlarına ise periyodik sınır koşulu tanımlanmıştır.

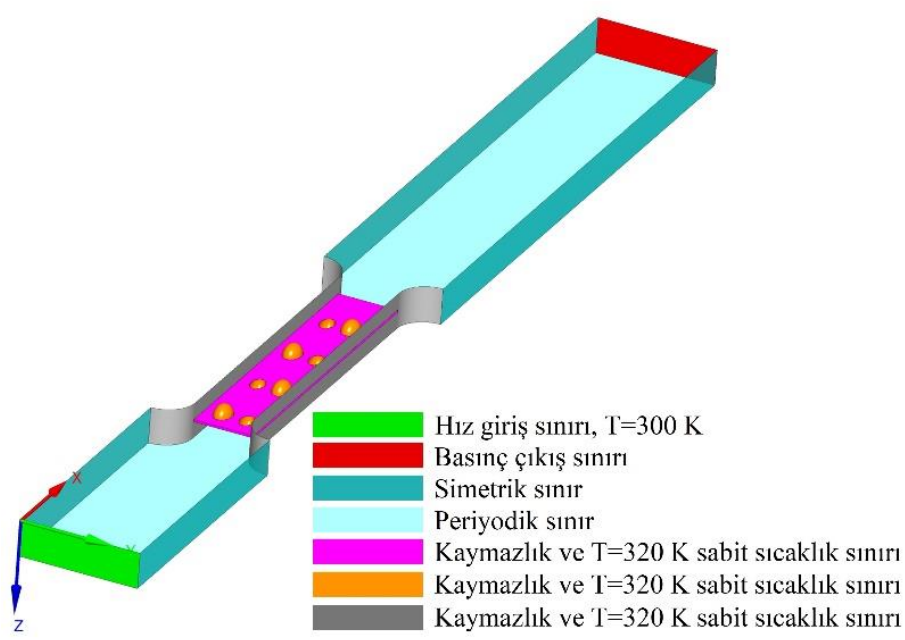

Şekil 3. Hesaplama alanı ve sınır koşullarının şematik gösterimi

RANS denklemleri aşağıda gösterilen sınır koşulları tanımlanarak çözülmüştür:

\section{$x$-ekseni boyunca:}

Girişte, hız girişi sınır koşulu:

$x=0, \quad u=u_{\text {gir }}=\operatorname{sabit}\left(u_{\text {gir }}=4,64,3,48,2,32\right.$,

$1,16 \mathrm{~m} / \mathrm{s}), v=w=0$

$T=$ sabit $=T_{\text {gir }}=300 \mathrm{~K}$

Çıkışta basınç çıkışı sınır koşulu:

$x=0,20, \frac{\partial u}{\partial x}=\frac{\partial v}{\partial x}=\frac{\partial w}{\partial x}=\frac{\partial T}{\partial x}=0, P=0$ (gösterge basınc1) 
y-ekseni boyunca:

Simetrik sınır koşulu:

$y=0$ ve $y=W=0,02 m, v=0, \frac{\partial u}{\partial y}=\frac{\partial w}{\partial y}=0, \frac{\partial T}{\partial y}=0$

z-ekseni boyunca:

Periyodik sınır koşulu:

$z=0$ ve $z=H=0,006 m, \quad u=v=w=0, \frac{\partial T}{\partial z}=0$,

$\frac{\partial P}{\partial z}=0$

Isı değiştirici duvarlarında kaymazlık sınır koşulu ve sabit sıcaklık sınır koşulu uygulanmıştır: $u=v=w=0$ ve $T=T_{d}=320 \mathrm{~K}$

Hesaplama alanında uygulanan sınır koşulları Şekil 3.'de ayrıca şematik olarak gösterilmiştir.

Sayısal hesaplamaları gerçek çalışma koşullarına uygun olarak gerçekleştirmek için 1sı değiştiricisinde boru malzemesi olarak bakır, kanat malzemesi olarak ise alüminyum seçilmiştir. Kullanılan malzemelerin termofiziksel özellikleri Tablo 1.'de sunulmuştur (Çengel vd., 2015).

Yapılan hesaplamalarda coupled şeması, simple ve simplec şemalarına göre her ne kadar iterasyon başına daha maliyetli olduğu tespit edilse de, coupled şeması ile diğerlerine kıyasla süreklilik, momentum ve enerji denklemi daha az iterasyon sayısında yakınsamıştır. Bu nedenle tüm hesaplamalarda coupled şeması uygulanmıştır. Hesaplamalar, süreklilik ve momentum denklemi artıkları $10^{-5}$ 'e, enerji denklemi artığ ise $10^{-8}$ 'e ulaşana kadar devam ettirilmiştir.

Tablo 1. Hesaplamalarda Kullanılan Malzemelerin Termofiziksel Özelikleri.

\begin{tabular}{lcccc} 
Malzeme & $\begin{array}{c}\text { Yoğunluk } \\
{\left[\mathrm{kgm}^{-3}\right]}\end{array}$ & $\begin{array}{c}\text { Özgül isı } \\
{\left[\mathrm{Jkg}^{-1} \mathrm{~K}^{-1}\right]}\end{array}$ & $\begin{array}{c}\text { Isıl iletkenlik } \\
{\left[\mathrm{Wm}^{-1} \mathrm{~K}^{-1}\right]}\end{array}$ & $\begin{array}{c}\text { Viskozite } \\
{\left[\mathrm{kgm}^{-1} \mathrm{~s}^{-1}\right]}\end{array}$ \\
\hline Hava & 1,134 & 1006,7 & 0,02710 & $1,67 \times 10^{-5}$ \\
Alüminyum & 2719 & 871 & 202,4 & - \\
Bakır & 8978 & 381 & 387,6 & -
\end{tabular}

\subsection{A $\breve{g}$ Yapısının Oluşturulması ve Sayısal Çalışmanın Doğruluğunun Belirlenmesi}

Sayisal hesaplamalarda fiziksel alan sonlu hacim elemanlarına bölünerek her bir eleman için yukarıda bahsi geçen RANS denklemlerinin çözümü elde edilir. Eleman sayısı arttıkça çözümlerin hassasiyeti artar. Ancak buna karşılık hesaplama maliyeti de önemli ölçüde artar. $\mathrm{Bu}$ nedenle ağ yapısını oluştururken hesaplama malyetini fazla arttırmadan çözümlerin hassasiyetini arttırmak için uygulanabilecek en uygun strateji özellikle akış alanı içerisinde hız ve sıcaklık farkının yüksek olduğu bölgelerin nispeten daha yoğun bir ağ yapısı ile oluşturulmasıdır. Hesaplamalarda kullanılan türbülans modeli nedeniyle akış alanı içerisinde akışkanın hızına bağlı olarak duvardan ilk hücre yüksekliği kontrol edilerek $y^{+} \cong 1,0$ olmasi sağlanmıştır. Ağ yapısı oluşturulurken duvarlarda inflation metodu kullanılarak elemanların uzunluk/yükseklik oranının 5/1'in altında olması sağlanmıştır (ANSYS Inc., 2018).

En uygun ağ yapısını belirlemek ve çözümlerin ağ yapısından bağımsızlığını tespit etmek için 4 farklı ağ yapısı oluşturulmuştur. Hesaplamalar $R e=2000$ 'de ve dairesel kesitli çukur kanatlı 1S1 değiştirici modelinde gerçekleştirilmiştir. Nicelik olarak 1s1 değiştiricisi duvarlarında ortalama $N u$ sayısı karşılaştırılmıştır. Sonuçların ağdan bağımsızlık çalışması Tablo 2.'de gösterilmiştir. Tablodan görüldüğ̈̈ gibi AĞ-3 kullanılarak hesaplanan $N u$ sayısı ile AĞ-4 kullanılarak hesaplanan Nu sayısı arasında fark \%1'in altındadır. Bu nedenle özellikle hesaplama maliyeti düşünülerek ağın yoğunluğunun arttırılmasına gerek duyulmamış ve bu çalışmanın sayısal hesaplamalarında AĞ-3 yapısı kullanılmıştır.
Sonuçların ağdan bağımsızlık çalışması sonucunda oluşturulan tipik bir ağ yapısı Şekil 4.'de gösterilmiştir.

Sayısal çözüm yönteminin doğruluğunu tespit etmek için düz yüzey üzerinden elde edilen ortalama $N u$ sayısı Eş. (13) (Çengel vd., 2015) ile elde edilen ortalama $N u$ sayısı ile karşılaştırılmıştır.

$\overline{N u}=0,664 \operatorname{Re}^{0,5} \operatorname{Pr}^{1 / 3} ; \operatorname{Re}<5 \times 10^{5}$ ve $0,6 \leq \operatorname{Pr} \leq 60$

Şekil 5.'den de görüleceği gibi yukarıda bahsedilen çözüm yöntemi ile düz yüzey üzerindeki ortalama $N u$ sayısı RNG $k-\varepsilon$ türbülans modeli kullanılarak en fazla \%8,29 ile kabul edilebilir bir hata oranında çözümlenebilmiştir. Literatürde de RNG $k-\varepsilon$ türbülans modeli hassas çözümler sunması nedeniyle 1S1 değiştiricileri ile ilgili yapılan sayısal çalışmalar için kabul görmüş bir RANS modelidir (Kumar vd., 2017; Skullong vd., 2016; G. Xie vd., 2013; J. Xie vd., 2020; Zhao vd., 2014). Bu da bu çalışmadaki sayısal çözüm yöntemin literatürle de tutarlı olduğunu ortaya koymaktadır. Bu nedenle yapılan bu çalışmada da RNG $k$ - $\varepsilon$ türbülans modeli kullanılmıştır. 
Tablo 2. Sonuçların ă̆dan bağımsızlık çalışması. (Grid independence study)

\begin{tabular}{lllll} 
& $\mathbf{A G}-\mathbf{1}$ & $\mathbf{A \breve { G }}-\mathbf{2}$ & $\mathbf{A} \breve{G}-3$ & $\mathbf{A G ̆}-\mathbf{4}$ \\
\hline Eleman say1S1 & $0.95 \times 10^{6}$ & $1,58 \times 10^{6}$ & $2.95 \times 10^{6}$ & $4,45 \times 10^{6}$ \\
$N u$ & 123.23 & 129.12 & 132.06 & 132.15
\end{tabular}

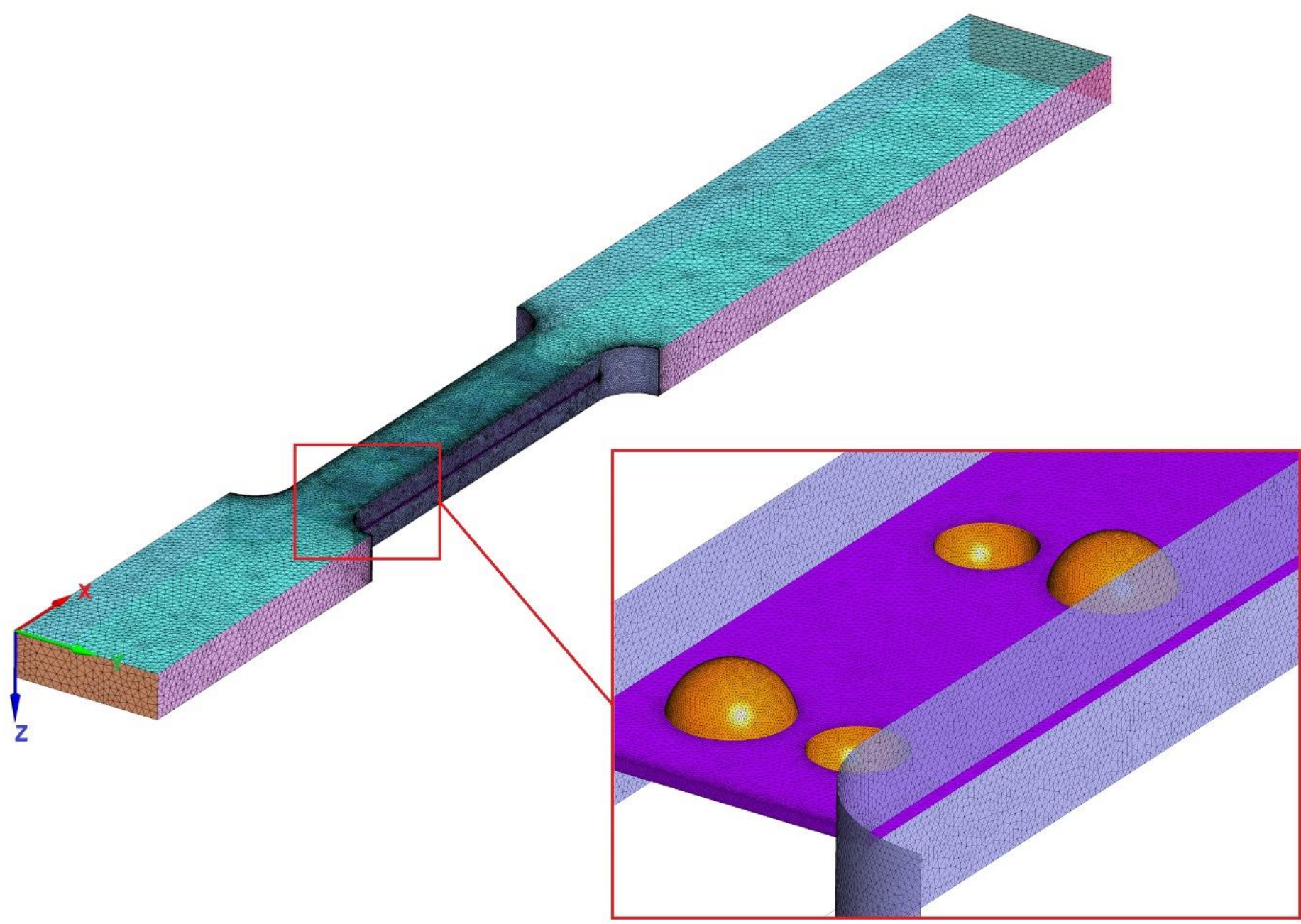

Şekil 4. A $\breve{g}$-3 ile oluşturulan tipik bir fiziksel modelin ăg yapısı.

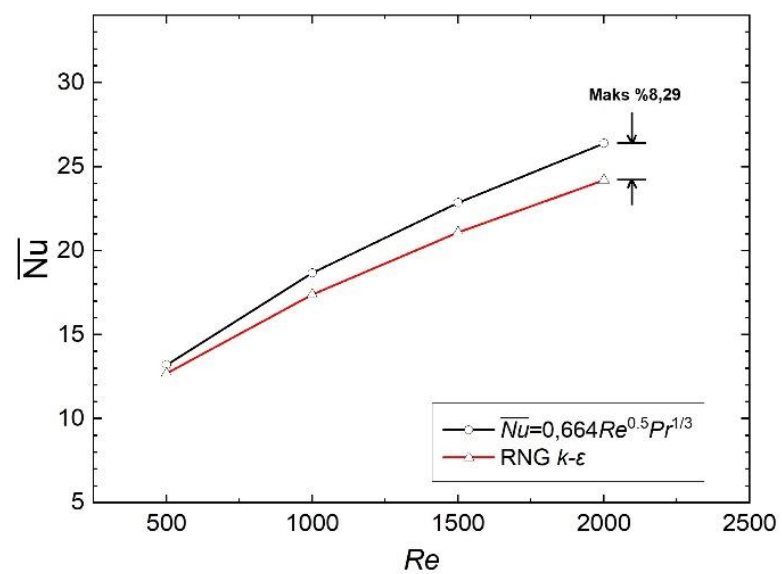

Şekil 5. Sayısal çözüm yönteminin düz yüzey üzerinde ortalama $\mathrm{Nu}$ sayısı bağıntısı ile karşılaştırılması (Çengel $v d$., 2015).

\section{Araştırma Sonuçları ve Tartışma}

\subsection{Akış Karakteristikleri}

Kanatl1-borulu 1S1 değiştiricilerinde kanat üzerindeki çukur/çıkıntı varlığının 1sı transferine olan etkisinin altında yatan nedeni ortaya çıkarmak için akış karakteristikleri ayrıntılı olarak incelenmiştir. Şekil 6(a).'da çukur/çıkıntıdan hemen sonra $(x / d=7,87)$ akış alanı içerisinde $R e=2000$ 'de $y z$-düzlemi üzerinde ortaya çıkan hız vektörleri gösterilmiştir. Bu bölgede düz yüzeyli kanatın hız vektörü incelendiğinde çukurlu/çıkıntılı kanata göre hava akışının nispeten daha sakin olduğu görülmektedir. Ancak şekilden de görüleceği üzere yüzey üzerinde çıkıntı varlığı akış alanı içerisinde bir çift girdap oluşumuna sebep olmuştur. Akış alanı içerisinde oluşan bu girdaplar, aşağı yönde ikincil bir hava akımını ortaya çıkarmış ve soğuk akışkanın bu sayede devamlı olarak yüzeye taşınmasına sebep olmuştur. Böylelikle düz yüzeye göre çukurlu/çıkıntılı yüzeyde soğuk akışkan sıcak yüzeyle daha fazla etkileşime girmiştir. Ayrıca, çıkıntıdan sonra aşağı yönde oluşan akımlar çıkıntı merkezi hizasında karşılaşarak yüzey 
üzerinde 1S1 transferinin azalmasına neden olan nispeten durgun bir alanın oluşumuna sebep olmuştur. Şekil 6(b). dikkatli incelendiğinde hava akışı kanat üzerinde ilerlerken çukurun artan $x$ doğrultusundaki kenarına çarpmakta ve hava akımı bu bölgede ayrılarak bir bölümü çukur içerisinde sirkülasyon oluşturmuştur. Benzer şekilde ana hava akışı kanal içerisinde ilerlerken çıkıntının ön yüzeyine çarparak ani olarak yön değiştirerek çıkıntının arka bölgesinde hava sirkülasyonu oluşturmuştur. Ana akışın doğrudan çukurun ve çıkıntının çarpmış olduğu bu yüzeylerinde sınır tabaka kalınlığının kanat yüzeyinin diğer bölgelerine göre nispeten daha ince olduğu değerlendirilebilir. Sonuç olarak, sınır tabaka kalınlığının azalması ise 1sı transfer hızının bu bölgelerde kanadın diğer bölgelerine göre nispeten daha yüksek olacağı anlamına gelir.

Akış alanı içerisinde yer alan bir engel akışın düzeninin bozulmasına ve akışın türbülansının artmasına neden olur. Bunu gösteren önemli akış karakteristiklerinden biri de türbülans kinetik enerjisidir. Çünkü akışkanın kayma gerilmesi nedeniyle akışın bir rejimden başka bir rejime geçmesi türbülans kinetik enerjinin üretilmesine neden olur. Şekil 7(a).'dan da görüleceği üzere düz kanat üzerinde hava akışının düzenli bir akış rejiminde olduğu ve türbülans kinetik enerjinin neredeyse hiç üretilmediği görülmektedir. Buna karşın özellikle ana akışın çukurun yüzeyine çarptığı bölgede ve çıkıntının arka bölümünde türbülans kinetik enerjisinin önemli ölçüde attığ 1 görülmektedir. Bu durum dairesel çukurlu/çıkıntılı kanat ile ovallik oranı $a / b=1,50$ olan çukurlu/çıkıntılı kanatta daha belirgin olmuştur. Sonuç olarak türbülans kinetik enerjileri karşılaştırıldığında çukurlu/çıkıntılı kanatın düz kanata kıyasla akışın türbülansını arttırarak 1s1 transfer hızının artmasına katkıda bulunacağı söylenebilir.

Dairesel çukurlu/çıkıntılı kanat üzerinde Farklı $R e$ sayılarında akış alanı içerisinde üretilen girdabın büyüklükleri Şekil 7(b).'de karşılaştırılmıştır. Şekilden görüleceği üzere kanat üzerinde yer alan çıkıntı özellikle yüksek Re sayısında akış alanı içerisinde bir çift girdap oluşumuna sebep olmuştur. Re sayısı azaldıkça girdabın da büyüklüğü azalmıştır.

\subsection{Isı transfer Performansı}

Şekil 8.'de $R e=2000$ 'de kanal duvarlarında Nusselt sayısı dağılımları gösterilmiştir. Şekil $8(a)$.'dan görüleceği üzere düz kanatta hava akışının yüzeyle ilk temas ettiği bölgeden itibaren 1sı transfer hızı akış boyunca önemli ölçüde azalmıştır. Buna karşın çukurlu/çıkıntılı kanatta ana akımın çukurun çarptığı kenarlarına yakın bölgelerinde ve ana akışın doğrudan çarptığı çıkıntının ön yüzeyinde sınır tabakanın düzeninin bozulması nedeniyle ısı transfer hızında önemli ölçüde artış olmuştur. Bununla birlikte çıkıntıdan sonra kanat yüzeyi üzerinde oluşan girdap ve dolayısıyla aşağı yönde ikincil hava akımlarının soğuk akışkanı devamlı olarak yüzeye taşıması nedeniyle yerel 1sı transfer hızı bu bölgelerde önemli ölçüde artmıştır. Buna karşın aşağı yönde ikincil hava akımların yüzey üzerinde karşılaşması ile yüzey üzerinde oluşan durgun alan bu bölgede akış yönü doğrultusunca 1S1 transfer hızını düşürmüştür.

Şekil 8(b).'de ise kanatl1-borulu 1s1 değiştiricinin boru duvarında gerçekleşen 1sı transfer dağılımı karşılaştırılmıştır. Düz kanatlı-borulu 1sı değiştiricinin boru duvarında kanadın alt ve üst yüzeylerinde simetrik bir 1sı transfer dağılımı elde edilmişken, çukurlu/çıkıntılı kanatlı-borulu 1S1 değiştiricinin boru duvarlarında homojen olmayan 1S1 transfer dağılımı elde edilmiştir. Bununla birlikte kanat yüzeyi üzerinde çukur/çıkıntı varlığı boru duvarında akış yönü boyunca düz kanata kıyasla yerel 1S1 transfer hızının artmasını sağlamıştır. Bunun nedeni, çukur/çıkıntının kanal içerisinde akışı yanal yönde daha fazla yayarak soğuk akışkanın boru duvarıyla daha fazla etkileşime sokmasına bağlanmıştır.

Isı değiştirici duvarlarında yanal ortalamalı $N u$ sayısı dağılımı Şekil 9.'da gösterilmiştir. Akış doğrultusunca verilen konumda yanal ortalamalı $N u$ sayısı yüzey üzerine $y$-ekseni boyunca çizilen doğru üzerindeki yerel $N u$ sayılarının ortalaması alınarak elde edilmiştir. Grafiklerin altında yer alan çukurlu/çıkıntılı yüzeyler $N u$ sayısındaki yükselişin yüzeyin hangi bölgesinde ortaya çıktığını göstermek için temsilen yerleştirilmiştir. Şekilden görüldüğü gibi yüzey üzerinde çukur/çıkıntının bulunduğu bölgede $N u$ sayısında ani bir yükselişin olduğu görülmektedir. Bunun nedeni bu bölgede ana akışın çıkıntının ön yüzüne ve çukurun akış yönüne göre arka kenarına doğrudan çarpmasıyla yerel olarak bu bölgede 1s1 transfer hızının artmasından kaynaklanmaktadır. Ayrıca iki çukur/çıkıntı arasında $N u$ sayısında yaşanan artış çıkıntı/çukur vasitasıyla ortaya çıkan girdabın yaratmış olduğu aşağı yönde ikincil hava akımların soğuk akışkanı yüzeye düz kanata göre daha fazla taşımasından kaynaklanmaktadır. Şekil dikkatli incelendiğinde $R e=500$ 'de yüzey üzerindeki çukur/çıkıntı varlığı yanal ortalamalı $N u$ sayısında çukur/çıkıntı bölgesi haricinde önemli bir artışa neden olmamıştır. Ancak Re sayısının artmasıyla kanal içerisinde oluşan girdabın büyüklüğünün de artması sadece çukur/çıkıntı bölgesinde değil aynı zamanada kanat yüzeyinin tamamında 1Sı transfer hızındaki artışın daha belirgin olmasını sağlamıştır. Buna ilaveten, nispeten yüksek Re sayısında $(R e=2000)$ oval çukur/çıkıntı $(a / b=0,667)$, kanat üzerinde daha yüksek yanal ortalamalı $N u$ sayısı dağılımı elde edilmesini sağlamışken nispeten düşük $R e$ sayısında $(R e \leq 1500)$ dairesel çukur/çıkıntı daha yüksek yanal ortalamalı $N u$ sayısı dağılımının elde edilmesini sağlamıştır.

Çukurun/Çıkıntının ortalama 1sı transfer hızına etkisi Şekil 10.'da gösterilmiştir. Şekil 10(a).'dan görüldüğü üzere kanat üzerine çukur/çıkıntı yerleştirilmesi kanat üzerindeki 1sı transfer hızını boru duvarına kıyasla daha fazla arttırmıştır. Kanat üzerinde ortalama $N u$ sayısındaki en yüksek artış $R e=2000$ 'de \%36,41 ile $a / b=1,50$ ovallik oranındaki çukurlu/çıkıntılı kanat üzerinde elde edilmiştir. $R e=1500$ ve altındaki akışlarda ise kanat üzerindeki ortalama $N u$ sayısındaki en yüksek artış ise $a / b=0,667$ ovallik oranındaki çukurlu/çıkıntılı kanat üzerinde elde edilmiştir. Şekil 10(b) incelendiğinde kanat üzerine çukur/çıkıntı yerleştirilmesi boru duvarında ortalama $N u$ sayısındaki artışın en fazla $\% 7,10$ olduğunu göstermektedir. Is1 değiştiricinin tüm duvarlarının yüzeyinde ortalama ısı transfer hızındaki en yüksek artış ise \%26,63 ile $R e=1500$ 'de dairesel çukurlu/çıkıntılı kanat üzerinde elde edilmiştir. 


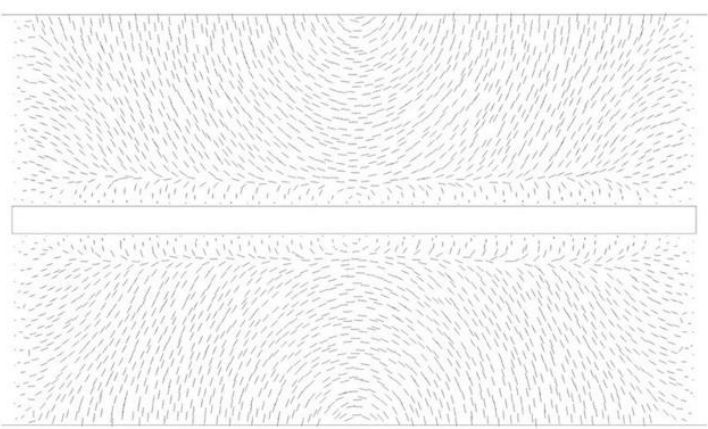

Düz Kanat

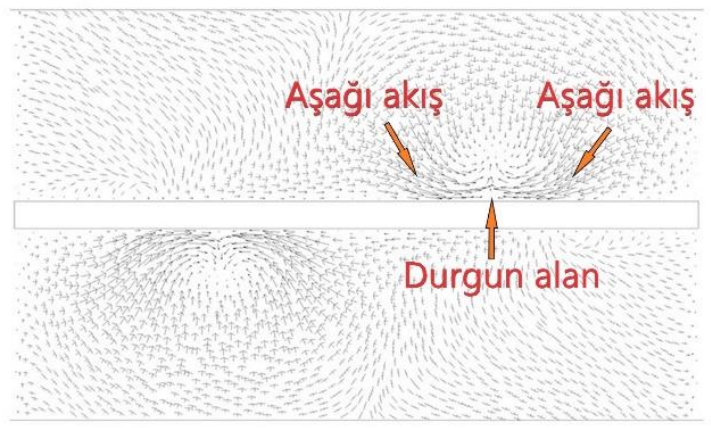

Dairesel çukurlu/çıkıntılı kanat

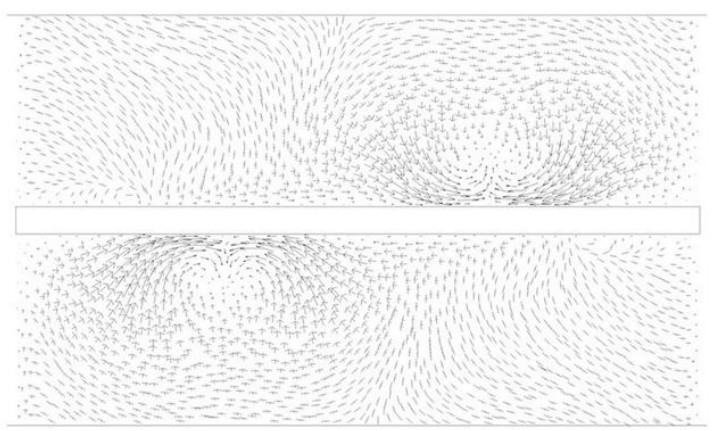

Oval çukurlu/çıkıntılı kanat $(a / b=0,667)$

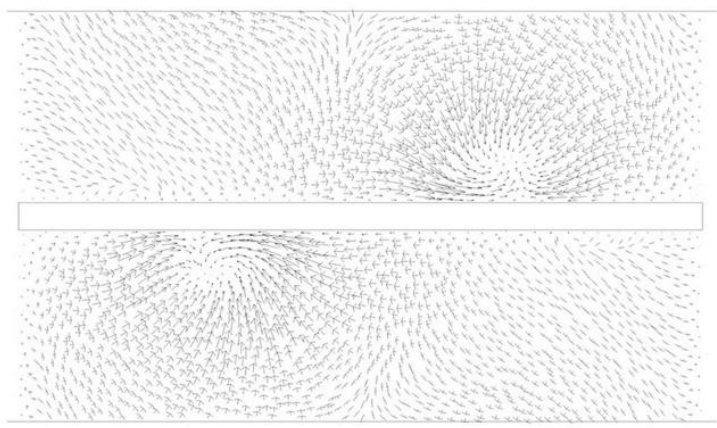

Oval çukurlu/çıkıntılı kanat $(a / b=1,50)$

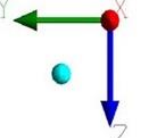

(a)

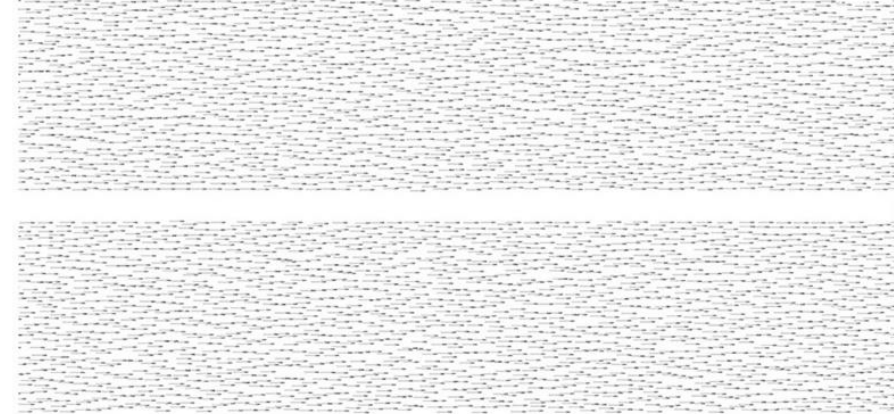

Düz Kanat

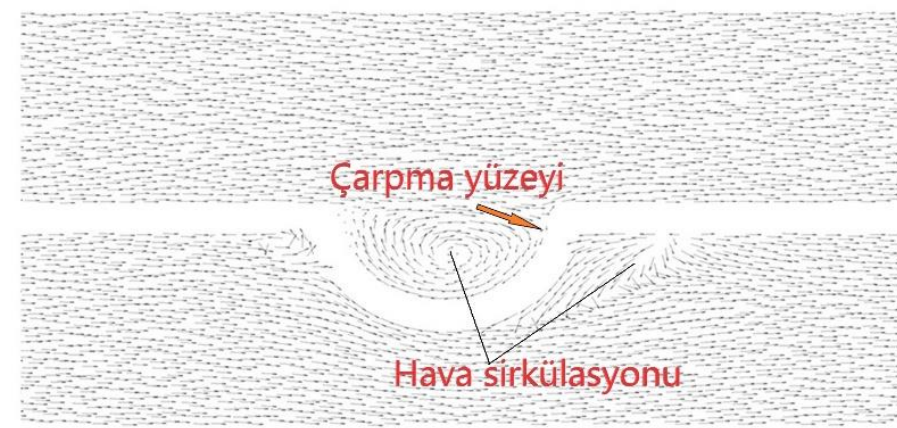

Dairesel çukurlu/çıkıntılı kanat

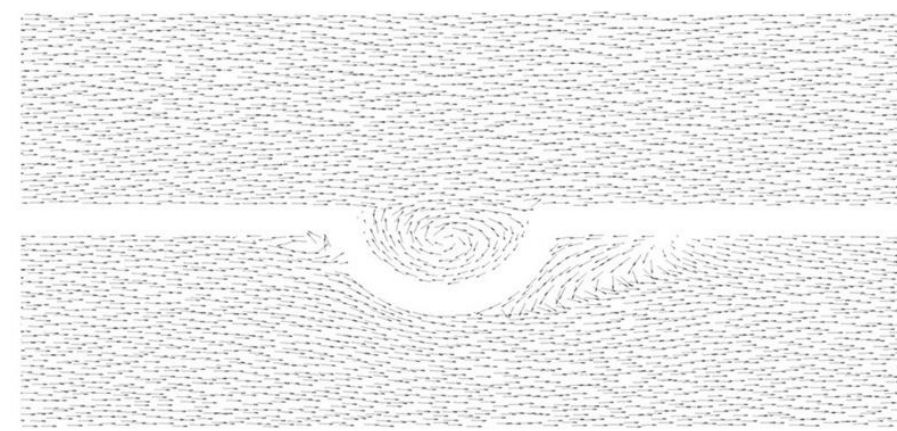

Oval çukurlu/çıkıntılı kanat $(a / b=0,667)$

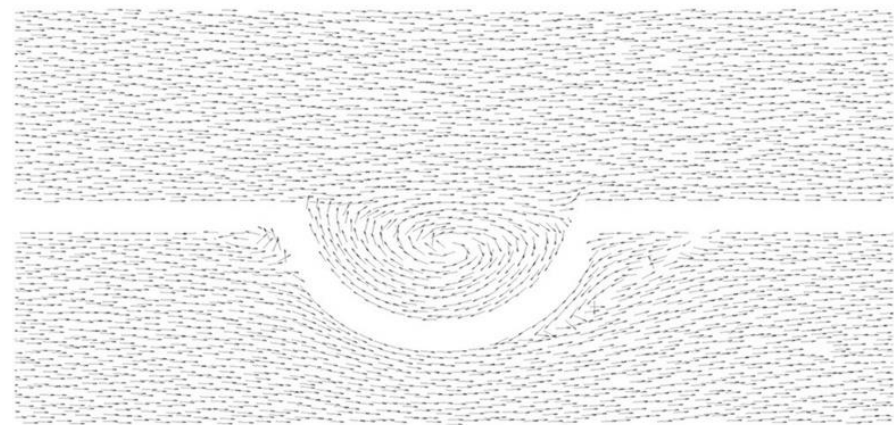

Oval çukurlu/çıkıntılı kanat $(a / b=1,50)$

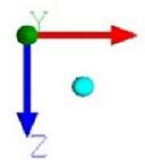

(b)

Şekil 6. Re=2000'de hız vektörlerinin karşılaştırılması, a) $x / d=7,87$ düzlemi üzerinde, b) y/d=1,67 düzlemi üzerinde. 


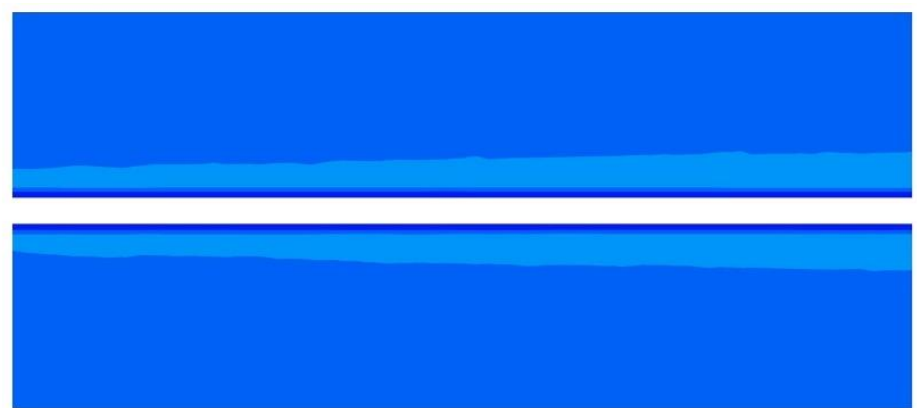

Düz kanat

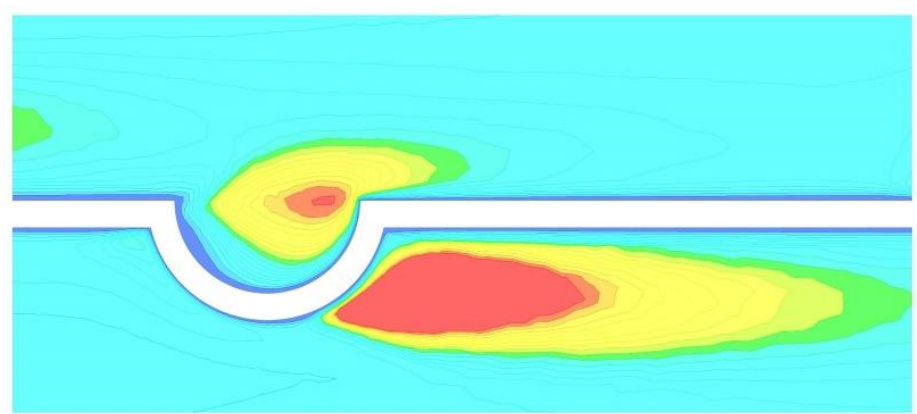

Dairesel çukurlu/çıkıntılı kanat

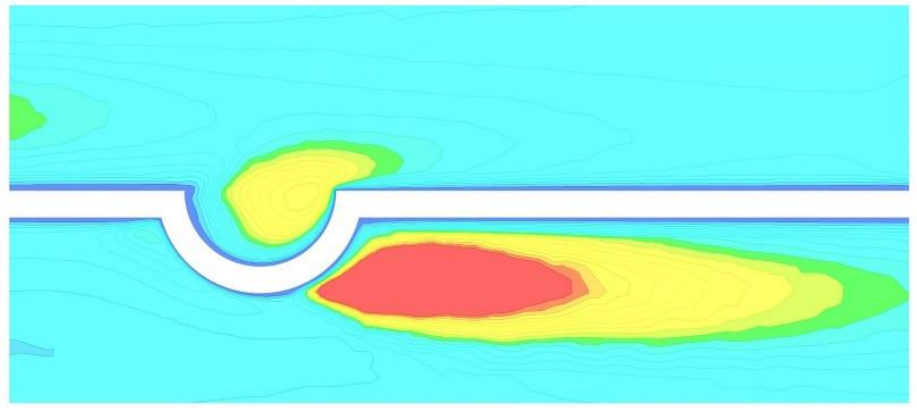

Oval çukurlu/çıkıntılı kanat, $a / b=0,667$

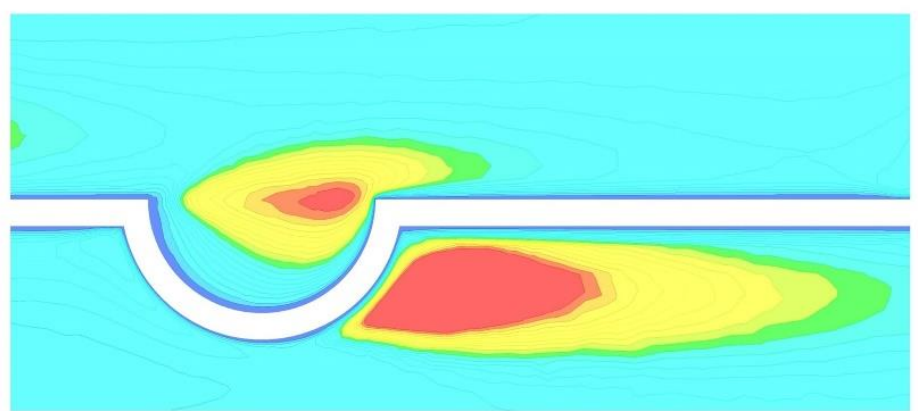

Oval çukurlu/çıkıntılı kanat, $a / b=1,50$

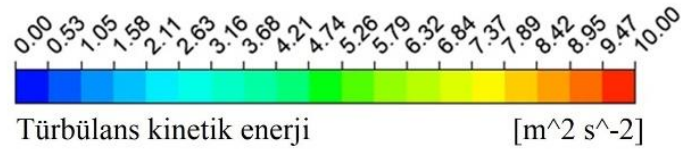

(a)

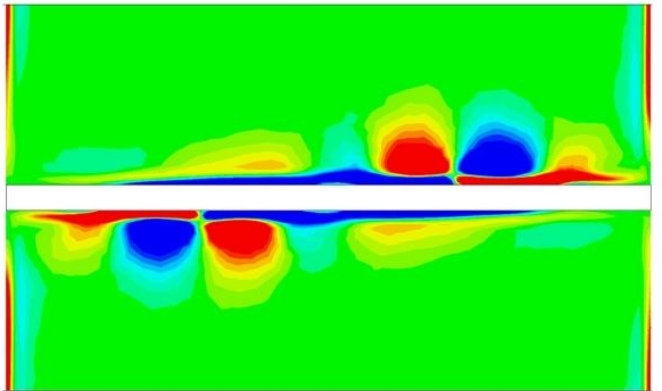

$R e=2000$

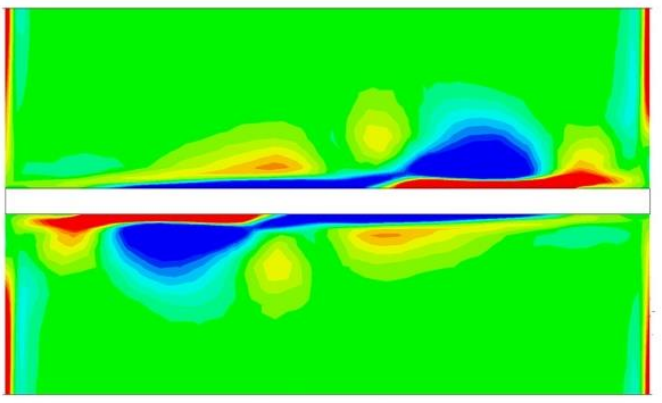

$R e=1500$

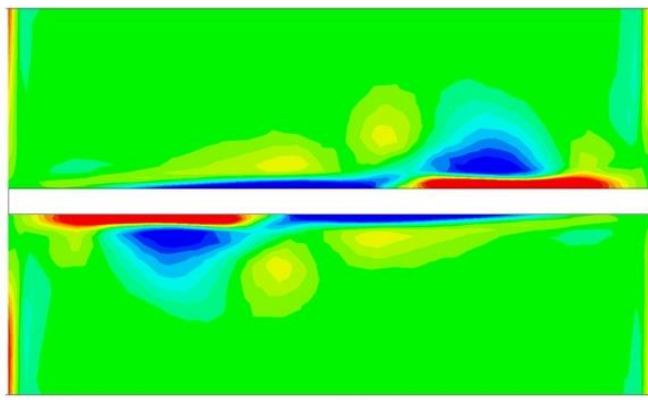

$R e=1000$
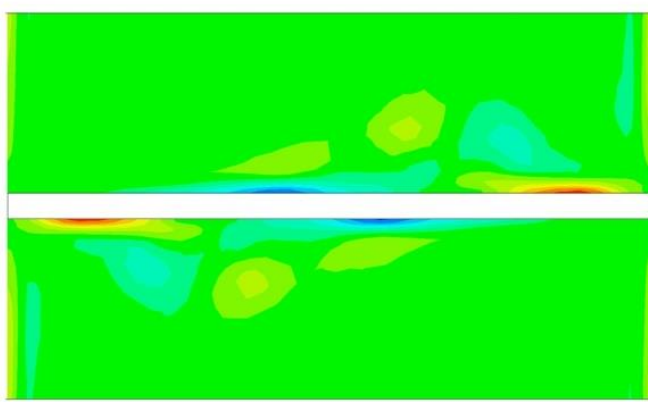

$R e=500$

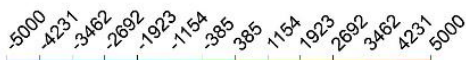

Girdap $\left[\omega_{\mathrm{x}}=5000 \mathrm{~s}^{\wedge}-1\right]$

(b)

Şekil 7. Aklş karakteristiklerinin karşılaştııılması, a) çukur/çıkıntının Re=2000'de türbülans kinetik enerjisine etkisi $(y / d=1,67)$, b) çukur/çıkıntının girdap oluşumuna etkisi $(x / d=7,87)$. 


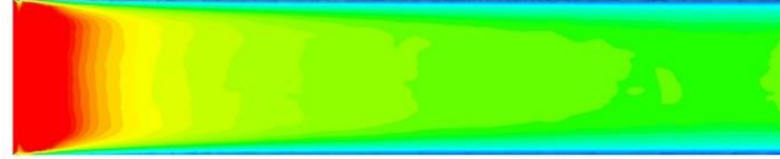

Düz kanat
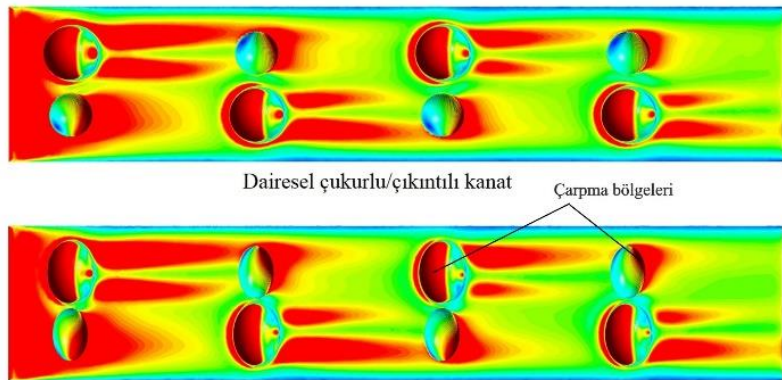

Oval çukurlu/çıkıntılı kanat, $a / b=0,667$

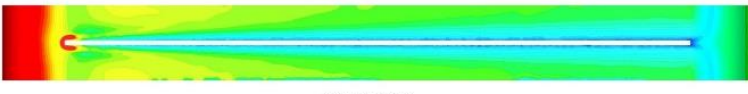

Düz kanat

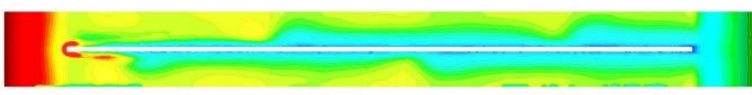

Dairesel çukurlu/çıkıntılı kanat

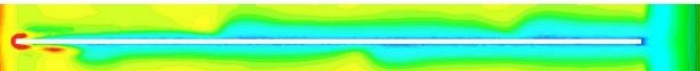

Oval çukurlu/çıkıntıı kanat, $a / b=0,667$

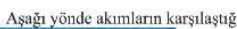

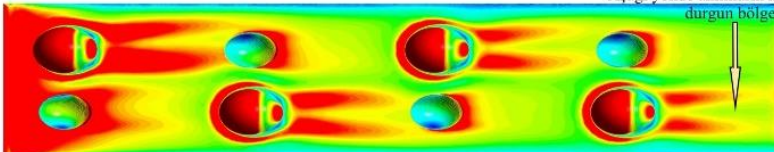

Oval çukurlu/çıkıntılı kanat, $a / b=1,50$
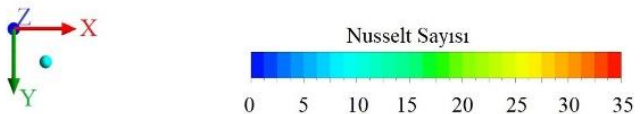

(a)

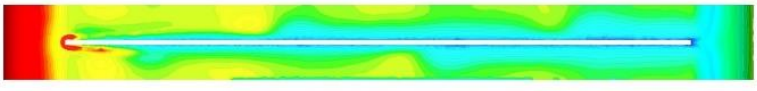

Oval çukurlu/çıkıntılı kanat, $a / b=1,50$

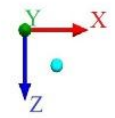

(b)

Şekil 8. Re=2000'de kanal duvarlarında Nu sayısı dağılımının karşılaştırılması, a) kanat duvarı (z/d=0,39), b) boru duvarı (y/d=2,089).

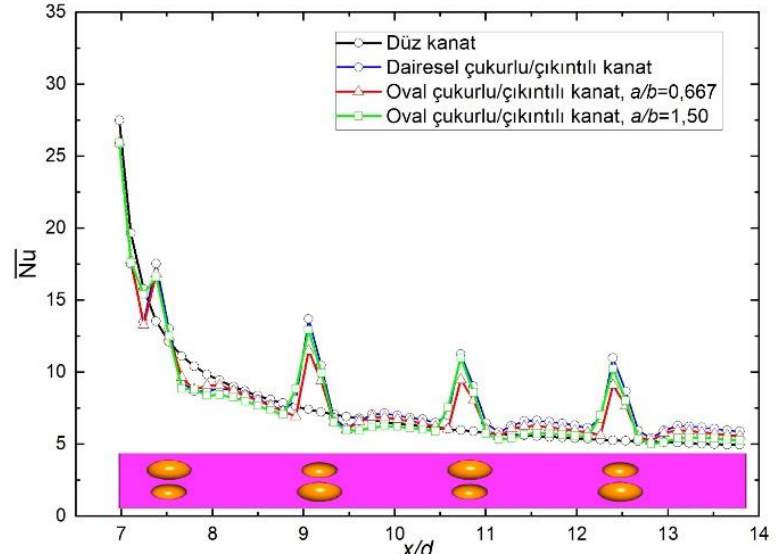

(a)

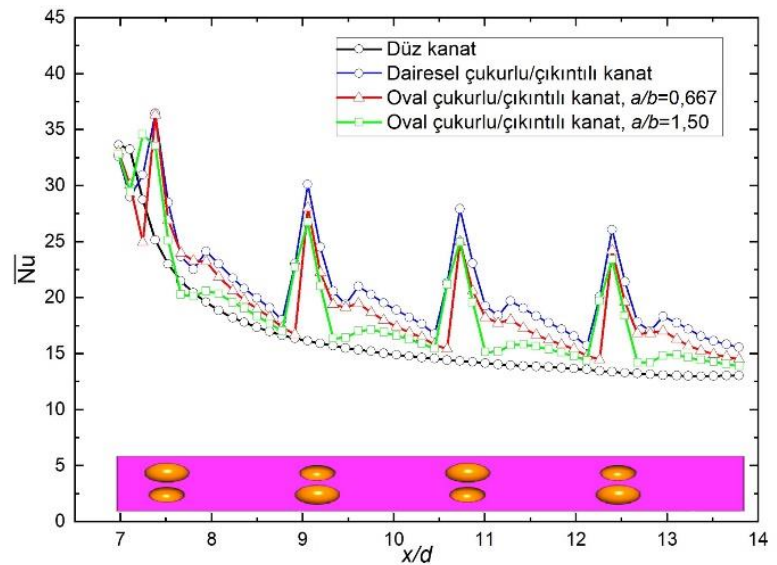

(c)

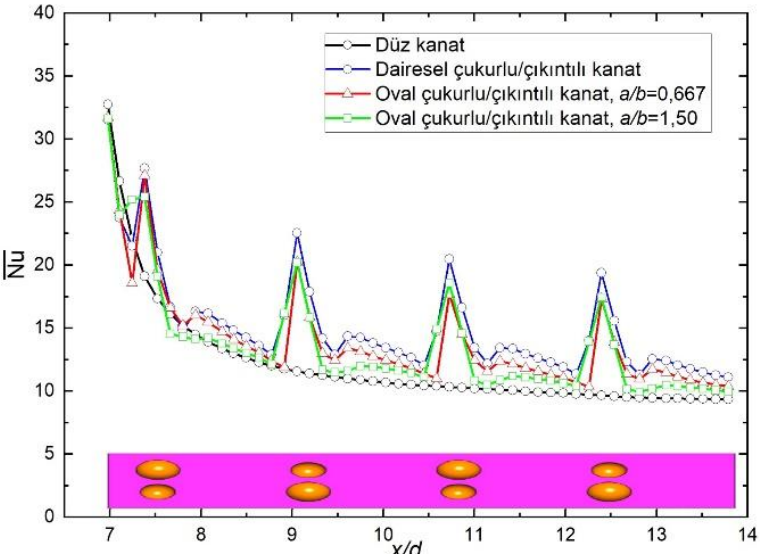

(b)

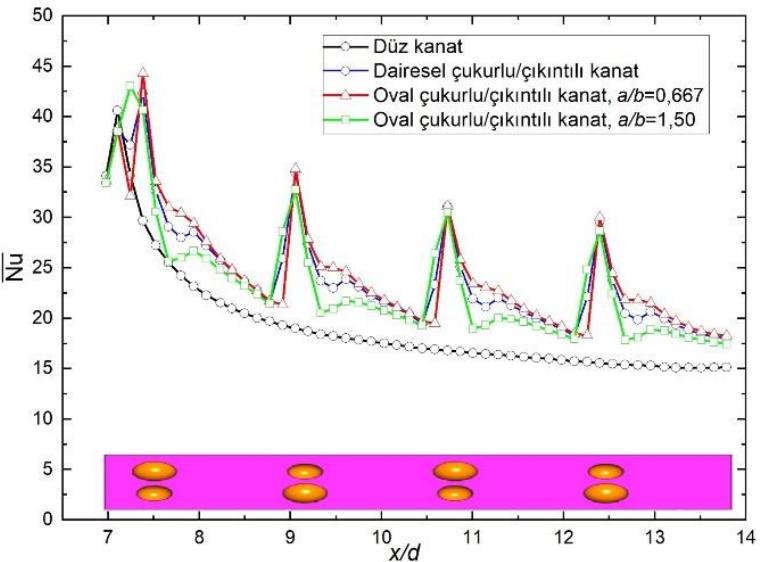

(d)

Şekil 9. Kanat ve boru duvarı üzerinde yanal-ortalamalı Nusselt sayısı dă̆ılımı, a) $R e=500$ için, b) $R e=1000 i c ̧ i n, c) R e=1500$ için, d) $R e=2000$ için. 


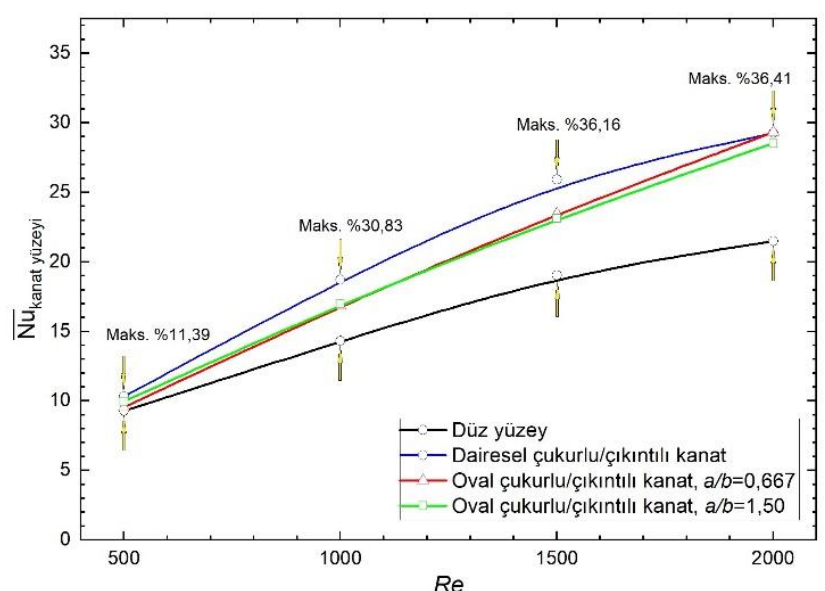

(a)

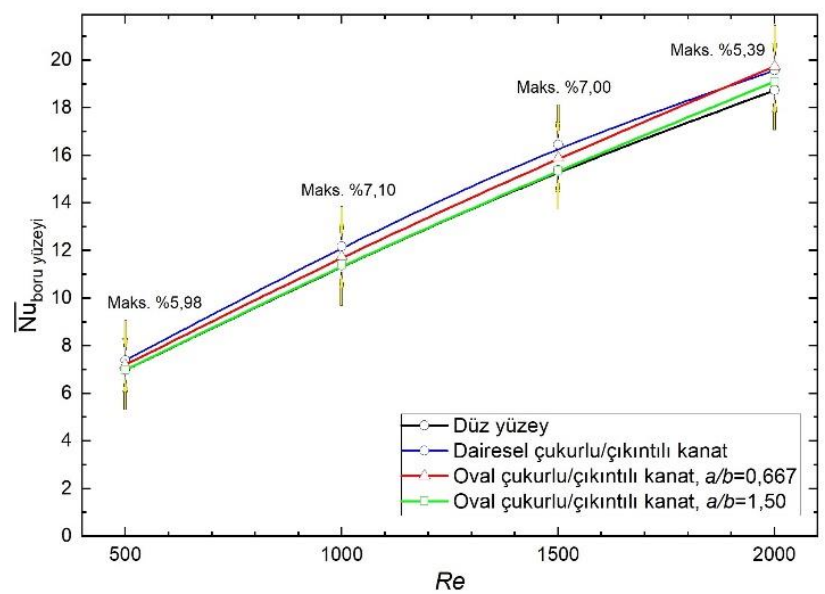

(b)

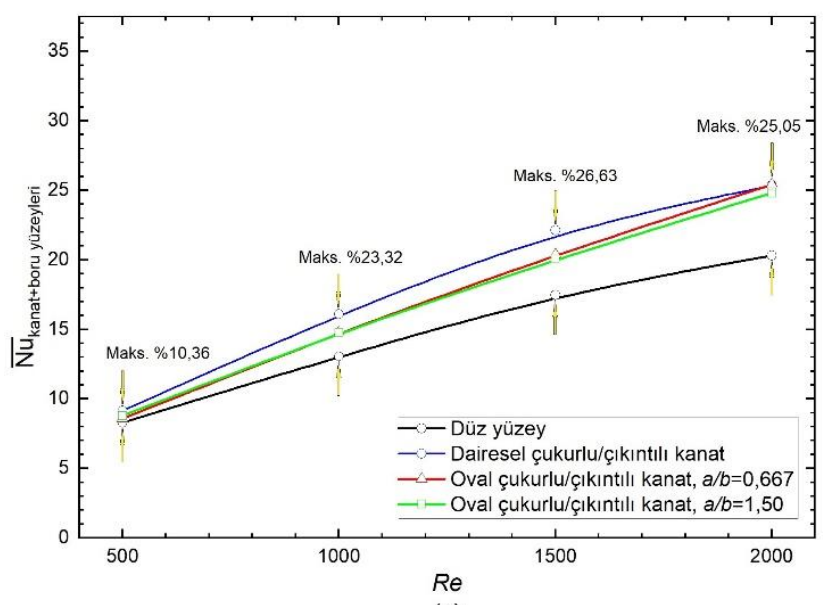

(c)

Şekil 10. Ortalama Nu sayılarının karşılaştırılması, a) kanat duvarl üzerinde, b) boru duvarl üzerinde, c) isl değiştirici duvarlarının tamamı üzerinde.

\subsection{Termal Performans Faktörü}

Bir 1sıtma/soğutma sisteminin tasarımında 1S1 transferini arttırmaya yönelik yapılacak olan değişiklikler sistemin basınç kaybındaki artışı da beraberinde getirebilir. Dolayısı ile sistemin tasarımında yapılacak değişikliğin anlamlı olup olmadığını ortaya çıkarmak için bu bölümde çukurlu/çıkıntılı kanat tasarımlarının Termal Performans Faktörü $(T P F)$ incelenmiştir. Isı transfer performansını arttırmak için öne sürülen tasarımın yararlı bir tasarım olarak değerlendirebilmek için $T P F$ 'nün 1'in üzerinde olması gerekir. TPF'nün 1'in altında olması basınç kaybında yaşanan artışın 1sı transferindeki artıştan daha fazla olduğu ve önerilen tasarımın 1S1 transferi arttırımı için yararlı bir tasarım olmadığını gösterir.

Sayısal çalışmaları gerçekleştirilen çukur/çıkıntının Termal Performans Faktörü aşağıdaki gibi hesaplanabilir (S. W. Chang vd., 2021; Maradiya vd, 2018; Tepe, 2021; Tepe, vd, 2020; Tepe, vd, 2020; Wang vd, 2001).

$$
T P F=\frac{N u_{1}}{N u_{0}}\left(\frac{f_{1}}{f_{0}}\right)^{-1 / 3}
$$

Çukurlu/çıkıntılı kanatın Termal Performans Faktörüne etkisi Şekil 11.'de gösterilmiştir. Şekilden görüleceği üzere $R e=500$ 'de öne sürülen tasarımlarda TPF 1'in altındadır. Bu nedenle düşük Re sayısında çukurlu/çıkıntılı kanatın ısı transferi arttırımı için yararlı bir tasarım olmadığı söylenebilir. Bunun sebebi, düşük Re sayısında akış alanı içerisinde oluşan girdabın büyüklüğü 1s1 transferinin iyileştirmesinde önemli bir etken olan aşağı yönde ikincil hava akımlarının yaratılmasında yetersiz kalmasıdır. Buna karşın Re sayısı arttıkça basınç kaybına kıyasla ısı transfer hızında ortaya çıkan artışın daha fazla olması $T P F$ 'nün 1'in üzerine çıkmasını sağlamıştır. Sonuç olarak kanatlı-borulu 1sı değiştiricileri için en yararlı tasarımın $R e=2000$ 'de $T P F=1,63$ ile dairesel çukurlu/çıkıntılı kanat tasarımının olduğu tespit edilmiştir.

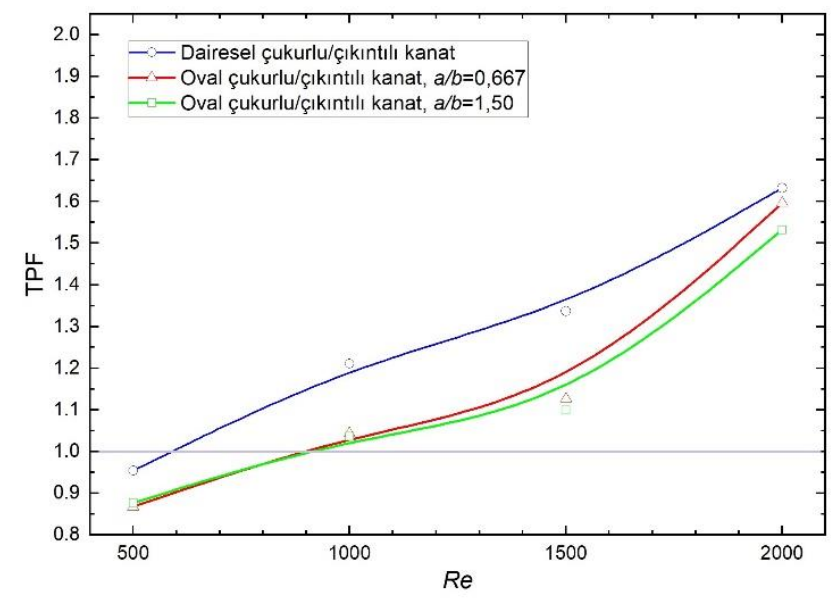

Şekil 11. Çukurun/çıkıntının Termal Performans Faktörüne etkisi.

\section{Sonuç}

$\mathrm{Bu}$ çalışmada kanatlı-borulu 1S1 değiştiricisinde kanat üzerinde oluşturulan çukurun/çıkıntının ısı transfer performansına etkisi sayısal olarak incelenmiştir. Isı değiştiricisinin borusu düz duvarlı olarak tasarlanmıştır. Çukurlar/çıkıntılar düz kanat üzerine çift sıralı olarak yerleştirilmiştir. Tasarım parametreleri olarak dairesel, $a / b=0,667$ ve $a / b=1,50$ olacak şekilde iki farklı ovallik oranı olmak üzere toplam üç farklı çukur/çıkıntı tasarımı incelenmiştir. Çukur derinlikleri ve çukurların kesit alanları sabit tutulmuş olup sırasıyla $1,40 \mathrm{~mm}$ ve $6,16 \mathrm{~mm}^{2}$ 'dir. Farklı akış hızlarında çukurun/çıkıntının ısı transfer performansına etkisini ortaya çıkarmak için hesaplamalar 500, 1000, 1500 ve 2000 olmak üzere dört farklı $R e$ sayısında gerçekleştirilmiştir. Sayısal hesaplamalar Ansys FLUENT 19.2 programında ve RNG $k$ - $\varepsilon$ türbülans modeli kullanılarak gerçekleştirilmiştir. 
Yapılan bu çalışmadan elde edilen sonuçlar aşağıda özetlenmiştir.

1. Kanat üzerinde yer alan çıkıntı akış alanı içerisinde bir çift girdap oluşumuna sebep olmuştur. Akış alanı içerisinde oluşan bu girdaplar kanat yüzeyine doğru ikincil hava akışının ortaya çıkmasını sağlamış ve soğuk akışkanın devamlı olarak yüzeye taşıyarak 1sı transferinin artmasına katkıda bulunduğu tespit edilmiştir.

2. Yanal ortalamalı $N u$ sayısı dağılımaları incelendiğinde özellikle çukur/çıkıntı bölgesinde yerel 1sı transfer hızında ani bir artışın olduğu tespit edilmiştir. Bunun sebebi ana akışın çıkıntının ön yüzüne ve çukurun akış doğrultusuna göre aşağı kenarına doğrudan çarpmasından kaynaklanmaktadır. Bir başka ifadeyle, yüzeye çarpan hava akışı bu bölgede sınır tabaka kalınlığını azaltarak ısı transfer hızının artmasına neden olmuştur.

3. Kanatl1-borulu 1Sı değiştiricisinin duvarlarında ortalama 1S1 transfer hızı incelendiğinde nispeten düşük $R e$ sayısında $(R e \leq 1500)$ dairesel kesitli çukur/çıkıntı oval çukurluya/çıkıntıya kıyasla daha yüksek 1sı trasfer hızının elde edilmesini sağlamıştır. Sonuç olarak kanal duvarlarının tamamında ortalama 1S1 transferindeki en yüksek artış \%26,63 ile $R e=1500$ 'de dairesel kesitli çukur/çıkıntı ile elde edilmiştir.

4. Termal Performans Faktörü sonuçları, 1sı transfer hızını arttırmak için kanat yüzeyine çukur/çıkıntı yerleştirmenin nispeten düşük $R e$ sayısında $(R e=500)$ uygun bir tasarım olmadı̆̆ını ortaya çıkarmıştır. Bunun sebebi, düşük Re sayısında 1sı transfer hızının artmasında önemli rolü olan aşağı yönde ikincil akışları ortaya çıkaracak büyüklükte girdap üretilememesine bağlanmıştır. Buna karşın hava akışının hızı arttıkça ikincil hava akışlarının üretilmesine bağlı olarak TPF de artmıştır. Sonuç olarak kanatlı-borulu 1S1 değiştiricisinde en yüksek $T P F$ 1,63 ile dairesel kesitli çukurlu/çıkıntılı kanat ile $R e=2000$ 'de elde edilmiştir.

\section{Kisaltmalar}

$\begin{array}{lll}A_{s} & \text { Yüzey alanı } & {\left[\mathrm{m}^{2}\right]} \\ A_{c} & \text { Kanal kesit alanı } & {\left[\mathrm{m}^{2}\right]} \\ d & \text { Hidrolik çap } & {[\mathrm{m}]} \\ D / d & \text { Boyutsuz çukur derinliği } & \\ f_{0} & \text { Düz kanatın sürtünme faktörü } & \\ f_{1} & \text { Çukurlu/çıkıntılı kanatın sürtünme faktörü } \\ h & \text { Ortalama taşınım ısı transfer katsayısı } & {\left[\mathrm{W} / \mathrm{m}^{2} \mathrm{~K}\right]} \\ H & \text { Kanat aralığ } & {[\mathrm{m}]} \\ H / d & \text { Boyutsuz çıkıntı yüksekliği } & \\ I & \text { Türbülans yoğunluğu } & \\ N u_{0} & \text { Düz kanatın ortalama Nu sayısı } & \\ N u_{1} & \text { Çukurlu/çıkıntılı kanatın ortalama } N u \text { sayısı } \\ P & \text { Kanal kesitinin çevre uzunluğu } & {[\mathrm{m}]} \\ p & \text { Akış doğrultusunca çukur/çıkıntı aralı̆̆ } & {[\mathrm{m}]} \\ s & \text { Yanal doğrultuda çukur/çıkıntı aralığ1 } & {[\mathrm{m}]} \\ t & \text { kanat kalınlığı } & {[\mathrm{m}]} \\ T_{\zeta} & \text { Hava çıkış sıcaklığı } & {[\mathrm{K}]}\end{array}$

Duvar sicaklığı

Hava giriş sıcaklığı

[K]

Ortalama yüzey sicaklığı $\quad[\mathrm{K}]$

Akışkanın yı̆̆ın sıcaklığı [K]

Ortalama akış hızı

$[\mathrm{m} / \mathrm{s}]$

Minimum kesit alanda akış hızı $\quad[\mathrm{m} / \mathrm{s}]$

Kinematik viskozite

$\left[\mathrm{m}^{2} / \mathrm{s}\right]$

Boru merkezleri arası mesafe [m]

Akış doğrultusu ekseni

[m]

Boyutsuz akış yönü mesafesi

yanal eksen

$[\mathrm{m}]$

boyutsuz duvar mesafesi

Akışa dik eksen

$[\mathrm{m}]$

\section{Semboller}

$\rho \quad$ Havanın yoğunluğu $\quad\left[\mathrm{kg} / \mathrm{m}^{3}\right]$

$\mu \quad$ Dinamik viskozite [Pa.s]

\section{Alt ve Üst Simgeler}

$\begin{array}{ll}\text { ç } & \text { çıkış } \\ \mathrm{g} & \text { giriş } \\ \mathrm{s} & \text { yüzey }\end{array}$

\section{Kaynakça}

ANSYS Inc. (2018). ANSYS Fluent, Release 19.1, Help System, Theory Guide. In ANSYS FLUENT 19.1.

Caliskan, S. (2013). Flow and heat transfer characteristics of transverse perforated ribs under impingement jets.

International Journal of Heat and Mass Transfer, 66(1), 244-260. doi: 10.1016/j.ijheatmasstransfer.2013.07.027

Carpio, J., \& Valencia, A. (2020). Heat transfer enhancement through longitudinal vortex generators in compact heat exchangers with flat tubes. International Communications in Heat and Mass Transfer, xxxx, 105035. doi: 10.1016/j.icheatmasstransfer.2020.105035

Çengel, Y. A., \& Ghajar, A. J. (2015). HEAT AND MASS TRANSFER FUNDAMENTALS \& APPLICATIONS. New York: McGraw-Hill Education.

Chang, L. M., Wang, L. B., Song, K. W., Sun, D. L., \& Fan, J. F. (2009). Numerical study of the relationship between heat transfer enhancement and absolute vorticity flux along main flow direction in a channel formed by a flat tube bank fin with vortex generators. International Journal of Heat and Mass Transfer, 52(7-8), 1794-1801. doi: 10.1016/j.ijheatmasstransfer.2008.09.029

Chang, S. W., Chiang, P., \& Cai, W. L. (2021). Thermal performance of impinging jet-row onto trapezoidal channel with different effusion and discharge conditions. International Journal of Thermal Sciences, 159(May 2020), 106590. doi: 10.1016/j.ijthermalsci.2020.106590

Chu, P., He, Y. L., Lei, Y. G., Tian, L. T., \& Li, R. (2009). Threedimensional numerical study on fin-and-oval-tube heat exchanger with longitudinal vortex generators. Applied Thermal Engineering, 29(5-6), 859-876. doi: 10.1016/j.applthermaleng.2008.04.021

Du, X., Feng, L., Li, L., Yang, L., \& Yang, Y. (2014). Heat transfer enhancement of wavy finned flat tube by punched 
longitudinal vortex generators. International Journal of Heat and Mass Transfer, 75, 368-380. doi:

10.1016/j.ijheatmasstransfer.2014.03.081

Du, X., Feng, L., Yang, Y., \& Yang, L. (2013). Experimental study on heat transfer enhancement of wavy finned flat tube with longitudinal vortex generators. Applied Thermal Engineering, 50(1), 55-62. doi: 10.1016/j.applthermaleng.2012.05.024

Eiamsa-Ard, S., \& Changcharoen, W. (2011). Analysis of turbulent heat transfer and fluid flow in channels with various ribbed internal surfaces. Journal of Thermal Science, 20(3), 260-267. doi: 10.1007/s11630-011-0468-3

Gentry, M. C., \& Jacobi, A. M. (1997). Heat Transfer Enhancement by Delta-Wing Vortex Generators on a Flat Plate: Vortex Interactions with the Boundary Layer. Experimental Thermal and Fluid Science, 14(3), 231-242. doi: 10.1016/S0894-1777(96)00067-2

He, Y. L., Han, H., Tao, W. Q., \& Zhang, Y. W. (2012). Numerical study of heat-transfer enhancement by punched winglet-type vortex generator arrays in fin-and-tube heat exchangers. International Journal of Heat and Mass Transfer, 55(21-22), 5449-5458. doi: 10.1016/j.ijheatmasstransfer.2012.04.059

Huisseune, H., T'Joen, C., De Jaeger, P., Ameel, B., De Schampheleire, S., \& De Paepe, M. (2013). Influence of the louver and delta winglet geometry on the thermal hydraulic performance of a compound heat exchanger. International Journal of Heat and Mass Transfer, 57(1), 58-72. doi: 10.1016/j.ijheatmasstransfer.2012.10.016

Huisseune, Henk, T'Joen, C., Jaeger, P. De, Ameel, B., Schampheleire, S. De, \& Paepe, M. De. (2013). Performance enhancement of a louvered fin heat exchanger by using delta winglet vortex generators. International Journal of Heat and Mass Transfer, 56(1-2), 475-487. doi: 10.1016/j.ijheatmasstransfer.2012.09.004

Jing, Q., Zhang, D., \& Xie, Y. (2018). Numerical investigations of impingement cooling performance on flat and non-flat targets with dimple/protrusion and triangular rib.

International Journal of Heat and Mass Transfer, 126(PartA), 169-190. doi: 10.1016/j.ijheatmasstransfer.2018.05.009

Kumar, A., Joshi, J. B., \& Nayak, A. K. (2017). A comparison of thermal-hydraulic performance of various fin patterns using 3D CFD simulations. International Journal of Heat and Mass Transfer, 109, 336-356. doi: 10.1016/j.ijheatmasstransfer.2017.01.102

Lemouedda, A., Schmid, A., Franz, E., Breuer, M., \& Delgado, A. (2011). Numerical investigations for the optimization of serrated finned-tube heat exchangers. Applied Thermal Engineering, 31(8-9), 1393-1401. doi: 10.1016/j.applthermaleng.2010.12.035

Li, J., Wang, S., Chen, J., \& Lei, Y. G. (2011). Numerical study on a slit fin-and-tube heat exchanger with longitudinal vortex generators. International Journal of Heat and Mass Transfer, 54(9-10), 1743-1751. doi: 10.1016/j.ijheatmasstransfer.2011.01.017

Li, M. J., Zhou, W. J., Zhang, J. F., Fan, J. F., He, Y. L., \& Tao, W. Q. (2014). Heat transfer and pressure performance of a plain fin with radiantly arranged winglets around each tube in fin-and-tube heat transfer surface. International Journal of Heat and Mass Transfer, 70, 734-744. doi: 10.1016/j.ijheatmasstransfer.2013.11.024

Lin, C. N., Liu, Y. W., \& Leu, J. S. (2008). Heat transfer and fluid flow analysis for plate-fin and oval tube heat exchangers with vortex generators. Heat Transfer

Engineering, 29(7), 588-596. doi:

10.1080/01457630801922279

Lin, Z. M., Liu, C. P., Lin, M., \& Wang, L. B. (2015). Numerical study of flow and heat transfer enhancement of circular tube bank fin heat exchanger with curved delta-winglet vortex generators. Applied Thermal Engineering, 88, 198-210. doi: 10.1016/j.applthermaleng.2014.11.079

Maradiya, C., Vadher, J., \& Agarwal, R. (2018). The heat transfer enhancement techniques and their Thermal Performance Factor. Beni-Suef University Journal of Basic and Applied Sciences, 7(1), 1-21. doi: 10.1016/j.bjbas.2017.10.001

Modi, A. J., Kalel, N. A., \& Rathod, M. K. (2020). Thermal performance augmentation of fin-and-tube heat exchanger using rectangular winglet vortex generators having circular punched holes. In International Journal of Heat and Mass Transfer (Vol. 158). doi: 10.1016/j.ijheatmasstransfer.2020.119724

Moreno, R. R., Pérez, A. M., \& Pérez, R. B. (2020). Numerical optimization of a heat exchanger with slit fins and vortex generators using genetic algorithms. In International Journal of Refrigeration (Vol. 119, pp. 247-256). doi: 10.1016/j.ijrefrig.2020.07.023

Rao, Y., Wan, C., \& Xu, Y. (2012). An experimental study of pressure loss and heat transfer in the pin fin-dimple channels with various dimple depths. In International Journal of Heat and Mass Transfer (Vol. 55, Issues 23-24, pp. 6723-6733). doi: 10.1016/j.ijheatmasstransfer.2012.06.081

Singh, P., \& Ekkad, S. (2016). Effects of Rotation on Heat Transfer due to Jet Impingement on Cylindrical Dimpled Target Surface. ASME Turbo Expo 2016: Turbomachinery Technical Conference and Exposition, 49798, V05BT16A010. Retrieved from http://dx.doi.org/10.1115/GT2016-57145

Sinha, A., Chattopadhyay, H., Iyengar, A. K., \& Biswas, G. (2016). Enhancement of heat transfer in a fin-tube heat exchanger using rectangular winglet type vortex generators. International Journal of Heat and Mass Transfer, 101, 667681. doi: 10.1016/j.ijheatmasstransfer.2016.05.032

Skullong, S., Thianpong, C., Jayranaiwachira, N., \& Promvonge, P. (2016). Experimental and numerical heat transfer investigation in turbulent square-duct flow through oblique horseshoe baffles. Chemical Engineering and Processing: Process Intensification, 99, 58-71. doi: 10.1016/j.cep.2015.11.008

Tepe, A. Ü. (2021). Numerical investigation of a novel jet hole design for staggered array jet impingement cooling on a semicircular concave surface. International Journal of Thermal Sciences, 162(December 2020), 106792. doi: 10.1016/j.ijthermalsci.2020.106792

Tepe, A. Ü., Uysal, Ü., Yetişken, Y., \& Arslan, K. (2020). Jet impingement cooling on a rib-roughened surface using extended jet holes. Applied Thermal Engineering, 178(June), 115601. doi: https://doi.org/10.1016/j.applthermaleng.2020.115601

Tepe, A. Ü., Yetişken, Y., Uysal, Ü., \& Arslan, K. (2020). Experimental and numerical investigation of jet impingement cooling using extended jet holes. International Journal of Heat and Mass Transfer, 158. doi: 10.1016/j.ijheatmasstransfer.2020.119945

Tiwari, S., Maurya, D., Biswas, G., \& Eswaran, V. (2003). Heat transfer enhancement in cross-flow heat exchangers using 
oval tubes and multiple delta winglets. International Journal of Heat and Mass Transfer, 46(15), 2841-2856. doi: 10.1016/S0017-9310(03)00047-4

Wan, C., Rao, Y., \& Chen, P. (2015). Numerical predictions of jet impingement heat transfer on square pin-fin roughened plates. Applied Thermal Engineering, 80(1), 301-309. doi: 10.1016/j.applthermaleng.2015.01.053

Wang, S., Guo, Z. Y., \& Li, Z. X. (2001). Heat transfer enhancement by using metallic filament insert in channel flow. International Journal of Heat and Mass Transfer. doi: 10.1016/S0017-9310(00)00173-3

Wu, H., Ting, D. S. K., \& Ray, S. (2018). The effect of delta winglet attack angle on the heat transfer performance of a flat surface. International Journal of Heat and Mass Transfer, 120, 117-126. doi: 10.1016/j.ijheatmasstransfer.2017.12.030

Xie, G., Liu, J., Ligrani, P. M., \& Zhang, W. (2013). Numerical analysis of flow structure and heat transfer characteristics in square channels with different internal-protruded dimple geometrics. International Journal of Heat and Mass Transfer, 67, 81-97. doi: 10.1016/j.ijheatmasstransfer.2013.07.094

Xie, G., \& Sundén, B. (2010). Numerical predictions of augmented heat transfer of an internal blade tip-wall by hemispherical dimples. In International Journal of Heat and Mass Transfer (Vol. 53, Issues 25-26, pp. 5639-5650). doi: 10.1016/j.ijheatmasstransfer.2010.08.019

Xie, J., \& Lee, H. M. (2020). Flow and heat transfer performances of directly printed curved-rectangular vortex generators in a compact fin-tube heat exchanger. Applied Thermal Engineering, 180(July). doi: 10.1016/j.applthermaleng.2020.115830

Xie, Y., Qu, H., \& Zhang, D. (2015). Numerical investigation of flow and heat transfer in rectangular channel with teardrop dimple/protrusion. In International Journal of Heat and Mass Transfer (Vol. 84, pp. 486-496). doi: 10.1016/j.jheatmasstransfer.2015.01.055

Yakhot, V., Orszag, S. A., Thangam, S., Gatski, T. B., \& Speziale, C. G. (1992). Development of turbulence models for shear flows by a double expansion technique. Physics of Fluids A. doi: 10.1063/1.858424

Yang, Y., Ting, D. S. K., \& Ray, S. (2020). Heat transfer enhancement of a heated flat surface via a flexible strip pair. International Journal of Heat and Mass Transfer, 159. doi: 10.1016/j.jheatmasstransfer.2020.120139

Zhao, X. B., Tang, G. H., Ma, X. W., Jin, Y., \& Tao, W. Q. (2014). Numerical investigation of heat transfer and erosion characteristics for H-type finned oval tube with longitudinal vortex generators and dimples. In Applied Energy (Vol. 127, pp. 93-104). doi: 10.1016/j.apenergy.2014.04.033 